\title{
Aerosol classification using airborne High Spectral Resolution Lidar measurements - methodology and examples
} \author{
D. B. Harper ${ }^{1}$, and K. D. Froyd ${ }^{3}$ \\ ${ }^{1}$ NASA Langley Research Center, Hampton, VA, 23681, USA \\ ${ }^{2}$ Science Systems and Applications, Inc., Hampton, VA, 23666, USA \\ ${ }^{3}$ Chemical Science Division, ESRL, NOAA, Boulder, CO, USA \\ Correspondence to: S. P. Burton (sharon.p.burton@nasa.gov)
}

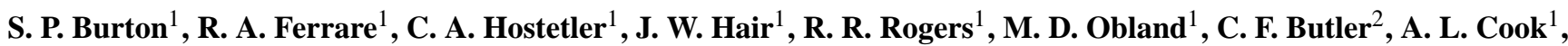

Received: 26 August 2011 - Published in Atmos. Meas. Tech. Discuss.: 7 September 2011

Revised: 2 December 2011 - Accepted: 9 December 2011 - Published: 10 January 2012

\begin{abstract}
The NASA Langley Research Center (LaRC) airborne High Spectral Resolution Lidar (HSRL) on the NASA B200 aircraft has acquired extensive datasets of aerosol extinction $(532 \mathrm{~nm})$, aerosol optical depth (AOD) $(532 \mathrm{~nm})$, backscatter (532 and $1064 \mathrm{~nm}$ ), and depolarization (532 and $1064 \mathrm{~nm}$ ) profiles during 18 field missions that have been conducted over North America since 2006. The lidar measurements of aerosol intensive parameters (lidar ratio, depolarization, backscatter color ratio, and spectral depolarization ratio) are shown to vary with location and aerosol type. A methodology based on observations of known aerosol types is used to qualitatively classify the extensive set of HSRL aerosol measurements into eight separate types. Several examples are presented showing how the aerosol intensive parameters vary with aerosol type and how these aerosols are classified according to this new methodology. The HSRLbased classification reveals vertical variability of aerosol types during the NASA ARCTAS field experiment conducted over Alaska and northwest Canada during 2008. In two examples derived from flights conducted during ARCTAS, the HSRL classification of biomass burning smoke is shown to be consistent with aerosol types derived from coincident airborne in situ measurements of particle size and composition. The HSRL retrievals of AOD and inferences of aerosol types are used to apportion AOD to aerosol type; results of this analysis are shown for several experiments.
\end{abstract}

\section{Introduction}

We introduce an aerosol classification scheme for airborne High Spectral Resolution Lidar (HSRL) measurements from the NASA Langley HSRL instrument. The ability to accurately characterize and discriminate aerosol type can improve both measurement retrievals and modeling, on both a regional and global scale. Since 2006, the NASA Langley HSRL has routinely participated in chemistry and radiationfocused field missions throughout North America, where its high accuracy, high resolution, vertically resolved measurements of aerosol provide vertical context for ground-based, in situ, and satellite observations of aerosols and clouds (e.g. Molina et al., 2010; Warneke et al., 2010). The HSRL also routinely provides validation for the Cloud-Aerosol $\mathrm{Li}$ dar with Orthogonal Polarization (CALIOP) lidar instrument aboard the Cloud-Aerosol Lidar and Infrared Pathfinder Satellite Observations (CALIPSO) satellite (Winker et al., 2009). The aerosol classification introduced here serves to enhance the input provided by HSRL in both of these roles. Furthermore, the HSRL serves as a test-bed for advanced satellite lidar instruments, and the advanced retrievals required for those measurements may benefit from aerosol classification like what is described here. For example, advanced lidar retrievals of microphysical properties from extinction and backscattering coefficients and depolarization at multiple wavelengths (Müller et al., 1999; Veselovskii et al., 2002), such as might be part of the future Aerosol Clouds and Ecosystems (ACE) Decadal Survey mission (National Research Council, 2007), would benefit from aerosol type information as a constraint to improve the retrieval efficiency. 
More than two decades ago, Sasano and Browell (1989) characterized different aerosol types using lidar, specifically a three-wavelength elastic backscatter lidar, with a retrieval method that optimizes the match between the shape of the backscatter profiles at the shorter wavelengths and that at $1064 \mathrm{~nm}$, which is relatively less sensitive to lidar ratio. Aerosols of five types were identified and classified. Later, the Lidar In-space Technology Experiment (LITE) (McCormick et al., 1993; Winker et al., 1996), the precursor to CALIPSO, provided the first opportunities to observe vertical distributions of aerosol globally. Kent et al. (1998) first described the long-range transport of biomass burning aerosols and characterized the optical properties using a similar lidar retrieval for LITE. Ground- and ship-based measurements by micropulse lidar (Spinhirne, 1993) provided case studies of biomass burning (Campbell et al., 2003), maritime and polluted maritime (Welton et al., 2002), and dust aerosols (Welton et al., 2000; Powell et al., 2000).

However, these lidars as well as the CALIOP instrument on the CALIPSO satellite are elastic backscatter lidars, for which it is not possible to independently measure the aerosol extinction and backscatter coefficients. To retrieve both, it is common to assume that the ratio of the two, the lidar ratio, is vertically homogeneous throughout the entire column or layer in question, and the lidar ratio is either prescribed or inferred using additional measurements as constraints. The need for more accurate lidar ratios to constrain this type of retrieval continues to provide motivation for aerosol classification and characterization studies.

Examples include in situ nephelometer measurements of backscattering plus integrated scattering and absorption measurements, which were used to calculate lidar ratios for various aerosol types (e.g. Anderson et al., 2000). Cattrall et al. (2005) moved beyond case studies using Aerosol Robotic Network (AERONET) sun photometer data sets to estimate lidar intensive parameters for specified aerosol types for use with spaceborne lidar retrievals. They followed Dubovik et al. (2002) who identified seasons and locations dominated by four key aerosol types and characterized the index of refraction and particle size distributions for those types using quality-controlled AERONET sun photometer data. The types identified by Dubovik et al. (2002) were urbanindustrial from fossil fuels, biomass burning from forest and grassland fires, wind-blown desert dust, and marine aerosol. Cattrall et al. (2005) expanded the set of aerosol types by adding a Southeast Asian type, distinct from urban-industrial pollution, exhibiting a greater number of large particles relative to fine particles. They also made this method of aerosol classification useful for lidar retrievals by calculating lidar parameters for these five types from retrievals of sky radiance and solar transmittance, and compared results to an extensive set of Raman lidar measurement case studies of particular types (Cattrall et al., 2005 and references therein).

The above studies characterize the optical properties of aerosols from samples of aerosol types that are identified by context. In contrast, an example of using lidar measurements to automatically classify aerosol types is given by Shimizu et al. (2004), who used the lidar depolarization measurements to differentiate spherical from non-spherical aerosol. A more sophisticated automated classification scheme is presented by Omar et al. (2005) who did a ( $k$-means) cluster analysis on 26 aerosol intensive variables derived from a comprehensive AERONET dataset to produce and characterize a set of six aerosol types. Measurements of the lidar ratio from ground-based Raman lidars along with aerosol depolarization values were shown to be useful for the separation of aerosol types by Groß et al. (2011), but from a more limited set of observations and aerosol types, including pure dust and biomass burning mixed with dust from the recent Saharan mineral dust experiment-2 (SAMUM-2) field mission. Weinzierl et al. (2011) classify aerosol from the same mission using these two lidar observables and absorption Ångström exponent calculated from in situ data. The classification methodology presented in the current work combines the strategies of contextual identification of selected cases with automated classification of the bulk of measurements, and will be described more fully in Sect. 4 .

The sun-photometer measurements used in many of the studies described above pertain to the entire integrated vertical column. Column-only measurements can cause biased estimates of lidar properties in situations with inhomogeneous aerosols. More recently, many additional high quality case studies characterizing vertically resolved aerosol optical properties of specific aerosol types world-wide have been made with ground-based Raman and HSRL lidars (e.g. Müller et al., 2007a and references therein; Amiridis et al., 2009; Noh et al., 2009; Tesche et al., 2009a,b; Giannakaki et al., 2010; Alados-Arboledas et al., 2011) and with airborne HSRL (Esselborn et al., 2009). The advantage of lidar is the ability to provide vertically resolved measurements, and Raman lidar (Ansmann et al., 1990) and High Spectral Resolution Lidar (Shipley et al., 1983; Grund and Eloranta, 1991; She et al., 1992) have the additional key advantage over backscatter lidar, in that they measure aerosol extinction and backscatter coefficients independently without using models or assumptions about aerosol type. Since extinction coefficients are measured, they also provide aerosol optical depth (AOD) measurements comparable to passive satellite-based (e.g. the Moderate-Resolution Imaging Spectroradiometer - MODIS, Remer et al., 2005 and the Multiangle Imaging Spectroradiometer - MISR, Kahn et al., 2005) and ground-based (e.g. Aerosol Robotic Network AERONET, Holben et al., 1998) observations (Burton et al., 2010).

Along with directly measured backscatter and extinction coefficients and AOD, the NASA Langley airborne High Spectral Resolution Lidar provides vertically resolved information about aerosol composition in the form of four aerosol intensive variables that depend only on aerosol type and not on concentration. This consistent set of four aerosol 
intensive parameters - the lidar ratio, aerosol depolarization at two wavelengths, and the ratio of aerosol backscatter at two wavelengths - provides qualitative information about the aerosol physical properties. Two channels of depolarization have not been used before for aerosol classification, and we find that this may help to separate the optically similar pollution and smoke aerosols, as discussed below in Sect. 4.2. In this report we describe how these measurements have been used to infer aerosol type.

The HSRL has flown on 18 field missions to date, and this has provided an extensive dataset of well-calibrated observations of aerosol types from diverse regions throughout North America. These observations are not limited to either day or night, unlike sunphotometer measurements. Since the intensive variables do not depend on the amount of aerosol loading, there is a much smaller effective limitation on the loading that can be used for classification than what was required for Dubovik et al. (2002) and Cattrall et al. (2005). An approximate minimum required signal level for this methodology is $0.0003 \mathrm{~km}^{-1} \mathrm{sr}^{-1}$ in aerosol backscattering, $0.015 \mathrm{~km}^{-1}$ in aerosol extinction, or 0.015 in aerosol optical thickness. The airborne HSRL is able to make aerosol extinction measurements down to within $300 \mathrm{~m}$ of the ground, thereby normally sampling a significant portion of the boundary layer where important aerosol types are located.

This is the first of two companion papers. Here we will describe how measurements acquired by the NASA Langley Research Center airborne High Spectral Resolution Lidar have been used to infer aerosol type and apportion AOD to aerosol type. In Sect. 2 of this paper, the NASA Langley airborne HSRL system is discussed, followed in Sect. 3 by a description of the HSRL measurements and how these are used to measure aerosol intensive parameters. In Sect. 4, the methodology for using these measurements to classify aerosol types is described, followed by a discussion of the particular aerosol types that are identified from the HSRL data. Examples of the aerosol classification are presented, followed by a discussion of these results in Sect. 5. After discussing the classification methodology and presenting examples of this classification in this paper, Ferrare et al. (2012) in the companion paper use the results of this HSRL-based aerosol classification to evaluate aerosol classifications derived from CALIPSO measurements and simulated by the GOCART aerosol model (Chin et al., 2002).

\section{NASA langley airborne High Spectral Resolution Lidar (HSRL)}

The LaRC airborne HSRL (Hair et al., 2008) uses the HSRL technique to independently retrieve aerosol and tenuous cloud extinction and backscatter without a priori assumptions on aerosol type or extinction-to-backscatter ratio. Hair et al. (2008) describe the instrument and measurement technique in detail. To briefly review, the HSRL technique (Shipley et al., 1983; Grund and Eloranta, 1991; She et al., 1992) measures aerosol extinction and backscatter independently, using a narrow-band iodine vapor filter to separate the broadened spectra of Cabannes scattering by molecules from the more narrowly peaked Mie scattering by aerosols (She, 2001). The observed molecular backscattering component is attenuated by extinction. Therefore, by comparison with the molecular backscattering from an atmospheric density profile obtained from the NASA Global Modeling and Assimilation Office (GMAO) or another source, the aerosol extinction coefficient profile is obtained. The LaRC HSRL employs the HSRL technique at $532 \mathrm{~nm}$ and the standard backscatter technique (Fernald et al., 1972; Klett, 1981; Fernald, 1984) at $1064 \mathrm{~nm}$, using an assumed lidar ratio of $35 \mathrm{sr}$ at $1064 \mathrm{~nm}$. The instrument also measures depolarization at both wavelengths. The return signal is split into components parallel and perpendicular to the polarization of the outgoing beam. The depolarization ratio here is defined as the ratio of the perpendicular to the parallel component. In contrast to standard backscatter lidars that are empirically calibrated by assuming that the aerosol contribution to backscatter is negligible or known at some altitude, the HSRL instrument is self-calibrating at $532 \mathrm{~nm}$ for measurements of aerosol and cloud backscatter and extinction. For the backscatter measurement, which derives from a ratio of the two signals, the assessment of the relative gain ratio between the molecular and backscattering channels is performed in flight by removing the iodine cell from the optical path and equalizing the input to the two channels. It is similarly self-calibrating at both 532 and $1064 \mathrm{~nm}$ for measurements of depolarization by using the procedure given by Alvarez et al. (2006), involving rotating the half-waveplate to $22.5^{\circ}$ to equalize the input to the "perpendicular" and "parallel" detector channels. The $532 \mathrm{~nm}$ extinction measurement is made from the derivative of the log of the molecular channel signal only, so the calibration constants are not required. The calibration of the $1064 \mathrm{~nm}$ aerosol and cloud backscatter measurement takes advantage of the internally calibrated HSRL measurement at $532 \mathrm{~nm}$ and therefore does not rely on an assumption of negligible or constant aerosol scattering in the calibration region. In contrast to ground-based lidar systems, the calibration region is close to the aircraft and therefore the attenuation is small. The instrument also features a unique autonomous boresighting system that insures the transmitter and receiver maintain co-alignment to very high accuracy during flight. A detailed description of this HSRL system and calibration and data retrieval techniques is provided by Hair et al. (2008). The vertical resolution of the backscatter coefficients and depolarization measurements is $30 \mathrm{~m}$, and the horizontal averaging is $10 \mathrm{~s}$ (about $1 \mathrm{~km}$ ) (Rogers et al., 2009). The aerosol extinction profiles have a vertical resolution of $300 \mathrm{~m}$, and the horizontal averaging is $60 \mathrm{~s}$ (about $6 \mathrm{~km}$ ) (Rogers et al., 2009). The vertical and horizontal resolutions can be varied to suit varying measurement needs. The extinction and lidar 
ratio profiles extend from approximately $300 \mathrm{~m}$ above the surface, as determined by a digital elevation dataset (GLOBE Task Team et al., 1999), to approximately $2500 \mathrm{~m}$ below the aircraft. The $300 \mathrm{~m}$ limit at the low end of the profile is to avoid ground contamination. The $2500 \mathrm{~m}$ near-range limit is to ensure full overlap between the outgoing laser and the receiver field of view. The backscatter coefficient and depolarization profiles extend further in each direction, from $500 \mathrm{~m}$ below the aircraft to $60 \mathrm{~m}$ ( 2 range bins) above the ground. The aerosol backscatter coefficients at the two wavelengths are combined to give a backscatter-related aerosol Ångström exponent.

$\stackrel{\circ}{\beta}_{\beta}=-\frac{\ln \left(\beta_{\alpha}^{532} / \beta_{\alpha}^{1064}\right)}{\ln (532 \mathrm{~nm} / 1064 \mathrm{~nm})}$

where $\beta_{\alpha}^{i}$ represents the aerosol backscatter coefficient at wavelength $i$. The subscript $\beta$ on the left-hand side indicates that this is a backscatter-related Ångström exponent to avoid confusion with the more commonly calculated extinction (or optical-depth) related Ångström exponent. The ratio $\beta_{\alpha}^{532}$ and $\beta_{\alpha}^{1064}$ is the "backscatter color ratio" used throughout this study. As stated above, the aerosol backscatter coefficient at $532 \mathrm{~nm}$ is a direct measurement made with the HSRL technique, while the backscatter coefficient at $1064 \mathrm{~nm}$ depends on a retrieval that uses an assumed lidar ratio. However, the standard backscatter retrievals at $1064 \mathrm{~nm}$ are less sensitive to errors in lidar ratio (Sasano and Browell, 1989), and the systematic error in $1064 \mathrm{~nm}$ backscatter is expected to be less than $15 \%$ at worst due to the uncertainty in the choice of lidar ratio. The backscatter ratio used here is therefore sufficient for the purpose of empirically separating aerosol classes.

In short, the HSRL provides vertically resolved measurements of the following extensive and intensive aerosol parameters:

- Extensive parameters: backscatter coefficient at 532 and $1064 \mathrm{~nm}$ with horizontal resolution of approximately $1 \mathrm{~km}$ and vertical resolution of approximately $30 \mathrm{~m}$; extinction coefficient at $532 \mathrm{~nm}$ with horizontal resolution of approximately $6 \mathrm{~km}$ and vertical resolution of approximately $300 \mathrm{~m}$; and total column optical depth at $532 \mathrm{~nm}$ derived by integrating the profile of extinction.

- Intensive parameters: $S_{\mathrm{a}}$ (aerosol lidar ratio) at $532 \mathrm{~nm}$ with resolutions matching those of the extinction coefficient given above, aerosol depolarization at $532 \mathrm{~nm}$ and $1064 \mathrm{~nm}$ with horizontal resolution of approximately $1 \mathrm{~km}$ and vertical resolution of approximately $30 \mathrm{~m}$; and the backscatter-related aerosol Ångström exponent (or, alternately, the backscatter color ratio), with resolution matching the backscatter coefficients above.

Validation of HSRL aerosol extinction measurements was performed by Rogers et al. (2009). They compared the
HSRL measurements with aerosol extinction derived from simultaneous measurements from the NASA Ames Airborne Tracking Sunphotometer (AATS-14) (Redemann et al., 2009) and in situ scattering and absorption measurements from the Hawaii Group for Environmental Aerosol Research (HiGEAR) in situ instruments (McNaughton et al., 2009). They found bias differences between HSRL and these instruments to be less than $3 \%\left(0.001 \mathrm{~km}^{-1}\right)$ at $532 \mathrm{~nm}$; rootmean-square (rms) differences at $532 \mathrm{~nm}$ were less than $50 \%$ $\left(0.015 \mathrm{~km}^{-1}\right)$.

\section{HSRL measurements}

The HSRL data analyzed in this article were acquired between March 2006 and September 2010. During that time, the airborne LaRC HSRL was deployed on the NASA Langley B200 King Air aircraft and acquired over $1000 \mathrm{~h}$ of data on over 330 science flights during eighteen field campaigns. HSRL continues to participate in field campaigns, but data beyond 2010 are not included in the analysis presented here. The campaigns used for this study include many processoriented field projects for NASA, the Department of Energy (DOE), the National Oceanic and Atmospheric Administration (NOAA), and the Environmental Protection Agency (EPA), as well as field projects devoted to CALIPSO validation. These totals include 101 successful validation flights for the CALIPSO program. Figure 1 shows the locations of these missions and Table 1 lists these field missions and the science flight hours associated with them. The diverse locations of these missions have enabled the HSRL to acquire measurements of several different aerosol types. For example, HSRL measurements of smoke during ARCTAS were described by Warneke et al. (2010) and Knobelspiesse et al. (2011); urban and dust aerosols during MILAGRO by Molina et al. (2010) and de Foy et al. (2011); and Saharan dust during TexAQS/GoMACCS by Liu et al. (2008), Parrish et al. (2009), and Burton et al. (2010). The HSRL acquired data below the aircraft, which normally flew at $9 \mathrm{~km}$ (m.s.l.); typical flight duration was 3.5-4 h.

Figure 2 shows an example of the suite of HSRL measurements acquired when the King Air flew over Mexico City between 17:38 and 17:52 UT on 13 March 2006. These measurements exhibit variations in aerosol type over Mexico City. The data shown in Fig. 2 were collected over a distance of about $115 \mathrm{~km}$. The aerosol backscatter and extinction coefficients are shown along with the four aerosol intensive parameters: aerosol depolarization at $532 \mathrm{~nm}$, extinction-tobackscatter ratio at $532 \mathrm{~nm}$, aerosol depolarization spectral ratio, and backscatter color ratio. The vertical and horizontal resolution and lower and upper altitude limits are as described in Sect. 2. These measurements show the variability of the various types of aerosols that were measured over the region. 
Table 1. Field campaigns for the NASA Airborne HSRL.

\begin{tabular}{lllrc}
\hline Field Mission & Location & Dates & $\begin{array}{r}\text { Number } \\
\text { Flights }\end{array}$ & $\begin{array}{c}\text { Flight } \\
\text { Hours }\end{array}$ \\
\hline MILAGRO & Mexico City & 1-31 Mar 2006 & 22 & 64.4 \\
CALIPSO Validation & Eastern USA & May-Aug 2006 & 20 & 56.7 \\
TexAQS/GOMACCS & Texas & 27 Aug-28 Sep 2006 & 28 & 89.0 \\
San Joaquin Valley & California & 8-20 Feb 2007 & 15 & 45.0 \\
CHAPS/CLASIC & Oklahoma City area & 3-29 Jun 2007 & 22 & 70.2 \\
CATZ CALIPSO Val. & Eastern USA & Jan-Aug 2007 & 20 & 49.9 \\
CALIPSO Validation & Caribbean & Jan-Feb 2008 & 13 & 42.2 \\
ARCTAS Spring & Alaska & 30 Mar-22 Apr 2008 & 27 & 97.9 \\
ARCTAS Summer & Canada & 24 Jun-13 Jul 2008 & 21 & 71.5 \\
Birmingham & Alabama & 12 Sep-15 Oct 2008 & 11 & 35.1 \\
CALIPSO Validation & Eastern USA & Jan-Apr 2009 & 13 & 39.7 \\
RACORO & Oklahoma & 21 May-27 Jun 2009 & 24 & 72.9 \\
Ocean Subsurface & Atlantic ocean & 14-29 Sep 2009 & 5 & 18.6 \\
CALIPSO Validation & Eastern USA & 8-22 Apr 2010 & 7 & 15.6 \\
CALIPSO Gulf Oil Spill & Gulf of Mexico & May, July 2010 & 6 & 19.7 \\
CalNEX & California & 11-24 May 2010 & 13 & 44.5 \\
CARES & California & 3-30 Jun 2010 & 25 & 80.1 \\
CALIPSO Validation & Caribbean & 4-27 Aug 2010 & 9 & 35.9 \\
\hline
\end{tabular}

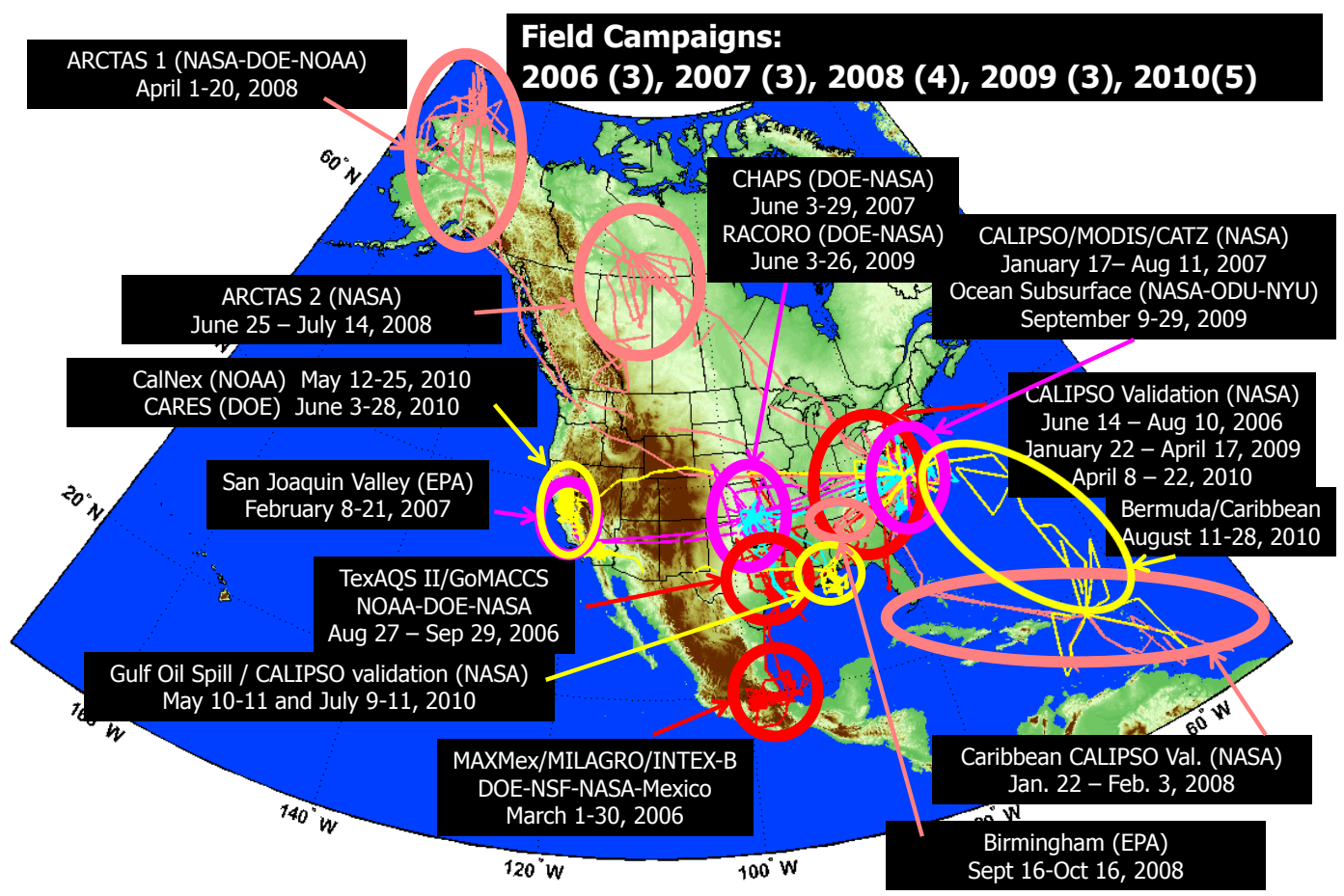

Fig. 1. Location of airborne HSRL flights and field experiments from 2006 through 2010.

The HSRL measurements of aerosol intensive parameters provide information about the particle physical properties. For example, backscatter color ratios typically are inversely related to aerosol particle sizes (Sasano and Browell, 1989; Sugimoto et al., 2002). Another intensive parameter, the depolarization ratio, is recognized as a discriminator of dust (Shimizu et al., 2004; Omar et al., 2009). High values of $30 \%$ to $35 \%$ depolarization at $532 \mathrm{~nm}$ for aerosol are indicative of nearly pure dust (Sugimoto and Lee, 2006; Liu et al., 2008; Freudenthaler et al., 2009), with smaller values 

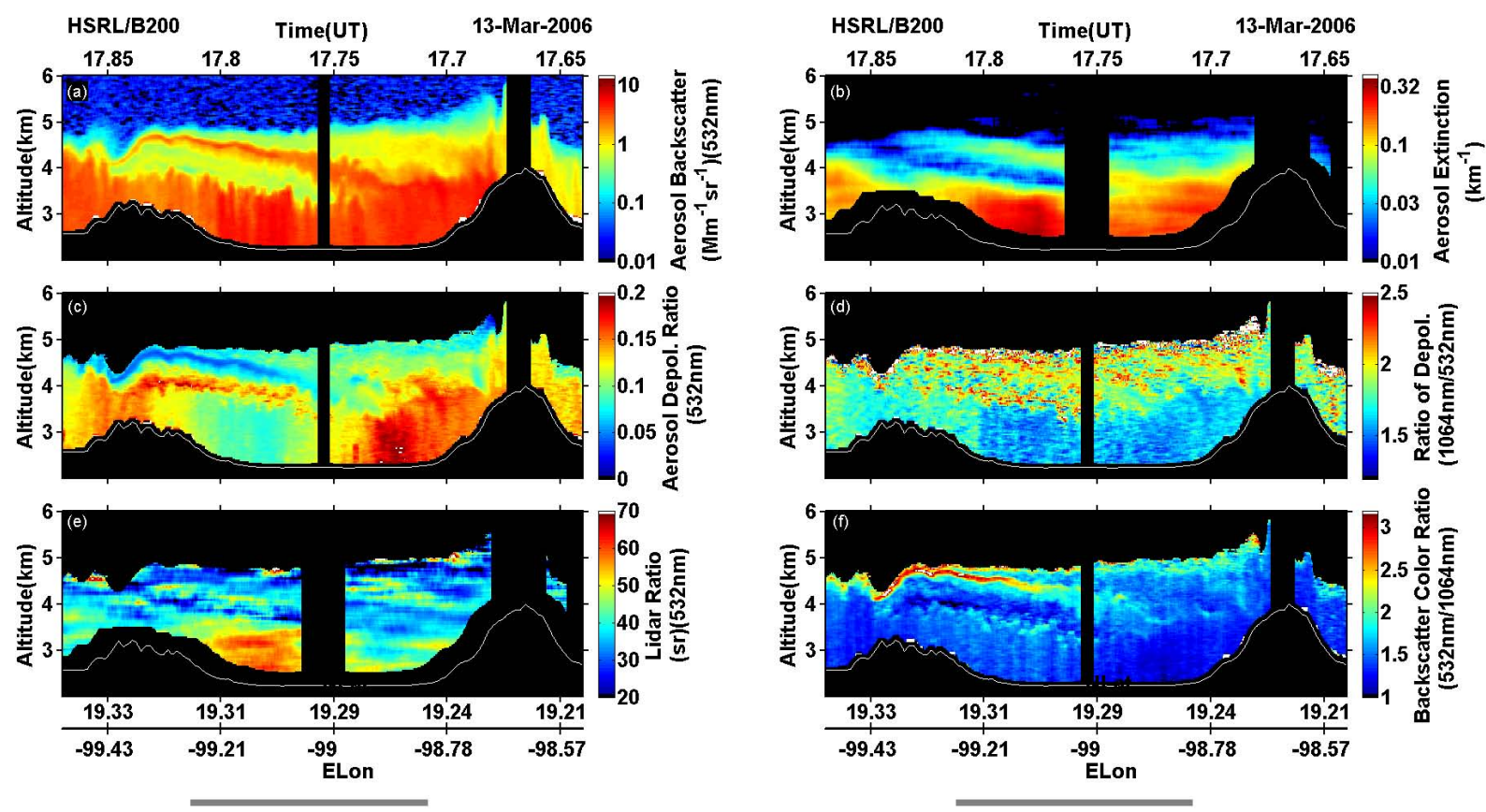

Fig. 2. Airborne HSRL measurements when the NASA B200 King Air flew over Mexico City between 17:38-17:52 UT on 13 March 2006 during the MILAGRO campaign. The aircraft flew from east (right) to west (left). The images cover a horizontal distance of about $115 \mathrm{~km}$. The gray bars at the bottom of the figure represent the approximate limit of the Mexico City Metropolitan area. (a) Aerosol backscatter coefficient $(532 \mathrm{~nm}),($ b) aerosol extinction coefficient $(532 \mathrm{~nm})$, (c) aerosol depolarization $(532 \mathrm{~nm})$, (d) aerosol depolarization spectral ratio $(1064 \mathrm{~nm} / 532 \mathrm{~nm})$, (e) $S_{\text {a }}$, the lidar ratio $(532 \mathrm{~nm})$, (f) aerosol backscatter color ratio $(532 \mathrm{~nm} / 1064 \mathrm{~nm})$. Variations in the parameters measured by the HSRL reflect variability in aerosol type.

that are still elevated above about $8-10 \%$ usually attributed to a mixture of dust with spherical particles (Murayama et al., 2003; Sugimoto and Lee, 2006; Tesche et al., 2009a). High depolarization can also indicate ice particles, as in cirrus clouds (e.g. Sassen, 1977; Sakai et al., 2003). Crystallized sea salt (Murayama et al., 1999; Sakai et al., 2010) and aged biomass burning and volcanic aerosols (Sassen, 2008) can also exhibit some depolarization, but with much smaller values. The degree of depolarization also varies with relative humidity, since hygroscopic swelling increases the sphericity of particles and decreases their depolarization (Murayama et al., 1996; Sassen, 2000). The spectral dependence of the depolarization ratio is dependent on particle size in the case of ice clouds (Somekawa et al., 2008) and on mixing ratio and spherical and non-spherical particle sizes in mixtures of dust and non-spherical particles (Sugimoto and Lee, 2006; Somekawa et al., 2008). Finally, the aerosol extinctionto-backscatter ratio, or lidar ratio, varies with aerosol size, shape, and composition; tropospheric aerosols typically have low values of approximately 20 to $50 \mathrm{sr}$ at $532 \mathrm{~nm}$ for coarse mode particles (i.e. sea salt, dust) and higher values for small and/or highly absorbing accumulation mode particles (Ackermann, 1998; Cattrall et al., 2005; Müller et al., 2007a and references therein).

For the example shown in Fig. 2, over the western part of the city, higher values of backscatter color ratio and the 532-nm lidar ratio $\left(S_{\mathrm{a}}\right)$ and lower values of the 532-nm depolarization suggest smaller, more spherically shaped particles (e.g. sulfate drops) more typically associated with urban/industrial pollution. Lower $S_{\text {a }}$ and higher depolarization values over the eastern part of the city suggest higher concentrations of dust. These measurements are consistent with WRF-Flexpart model simulations which also indicate urban emissions dominating in the western part of the city, with a mixture of biomass burning, urban emissions and dust in the east (see de Foy et al., 2011, Fig. 8). These HSRL measurements also clearly show the vertical and horizontal variability of aerosol intensive properties (e.g. 532-nm depolarization and backscatter color ratio) associated with thin elevated aerosol layers over the western section of Mexico City.

Figure 3 shows how the aerosol intensive properties measured by the HSRL varied during the various field experiments from March 2006 through 2010. Note, for example, how the aerosols observed over Mexico during the MILAGRO campaign had somewhat different characteristics than those observed over Houston during GOMACCS and the eastern US during the CALIPSO validation missions. The aerosols observed during MILAGRO typically had smaller lidar ratio and larger 532-nm depolarization than the aerosols observed over the eastern US. This indicates that the aerosols observed during MILAGRO were somewhat larger and more nonspherical and therefore most likely had 

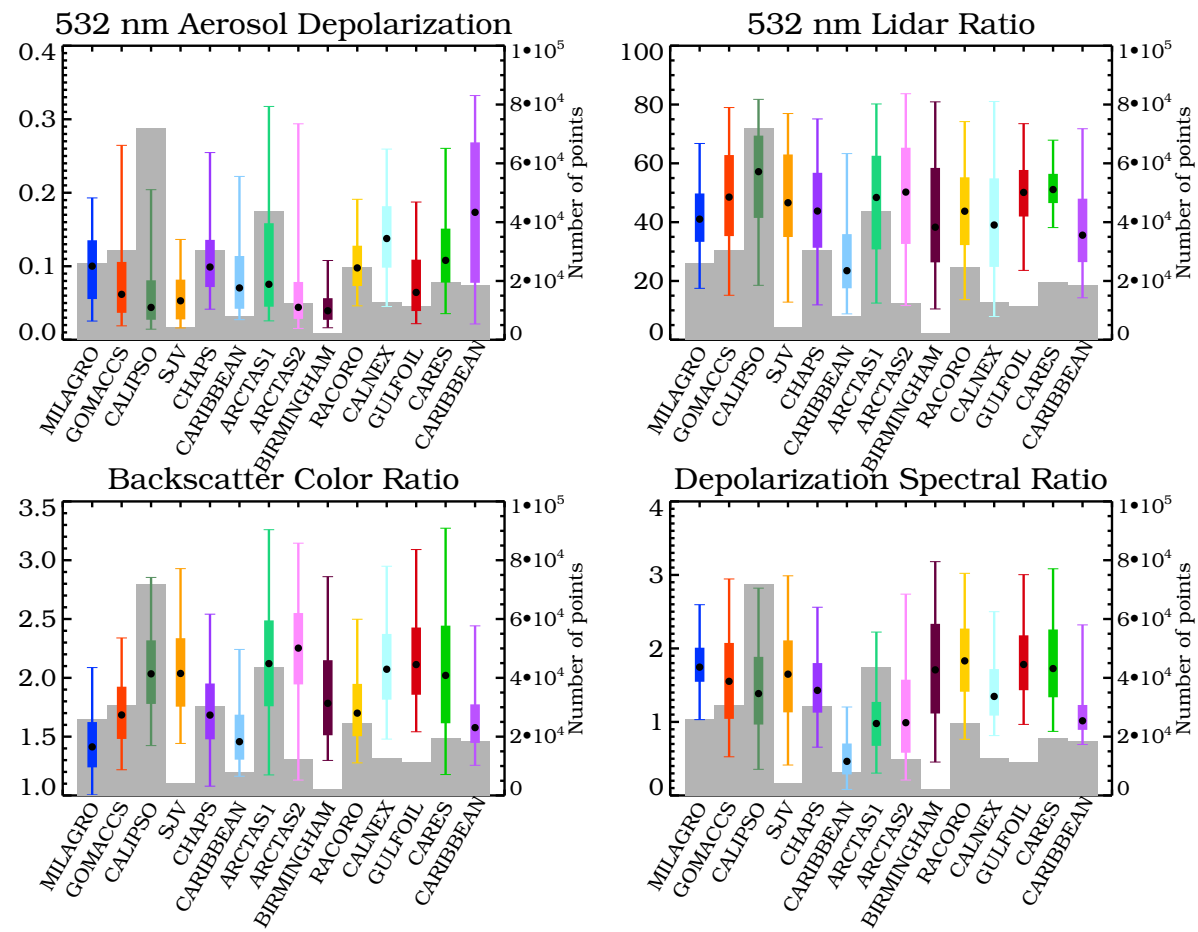

Fig. 3. Distributions of aerosol intensive parameters derived from HSRL measurements during recent field campaigns. Median values of each of the four intensive variables are shown for each mission (dots) along with the 25-75th percentiles (bars) and 5-95th percentiles (whiskers). The right-hand axis corresponds to the gray histogram bars, which show the number of observations for each field campaign. Several CALIPSO validation campaigns in the Eastern US and off the east coast have been grouped together in the single category "CALIPSO" in this figure. The two different Caribbean campaigns (2008 and 2010) are shown separately.

higher concentrations of dust (Molina et al., 2010; de Foy et al., 2011); conversely, the aerosols observed over the eastern and southeastern US typically were smaller and more spherical, consistent with urban aerosols. The lidar ratio varies as well, with larger values for the urban aerosols typically seen during the CALIPSO validation flights in the eastern US and somewhat smaller lidar ratio values seen during MILAGRO where more dust was present. As another example, the first Caribbean campaign, which made frequent measurements of maritime aerosol, exhibits much smaller lidar ratio and also a smaller spectral ratio of depolarization. Conversely, during ARCTAS the lidar ratio was large, typical of the smoke aerosol frequently seen during that campaign (Warneke et al., 2010; Shinozuka et al., 2010), and the backscatter color ratio was also high, indicating small particles. During the second Caribbean campaign, high values of aerosol depolarization reflect the large amount of Saharan dust observed. These results indicate that the aerosol intensive variables measured by HSRL vary with location and suggest that this variability can be used as an indicator of aerosol type. In the next section, we describe our methodology for using these HSRL measurements to infer aerosol types.

\section{Aerosol classification}

\subsection{Methodology}

As stated above, the four aerosol intensive variables used in the aerosol classification are the extinction-to-backscatter ratio, $S_{\mathrm{a}}$, at $532 \mathrm{~nm}$; the backscatter color ratio, which is the ratio of the backscattering coefficient at $532 \mathrm{~nm}$ to $1064 \mathrm{~nm}$; the aerosol depolarization at $532 \mathrm{~nm}$ (actually the natural logarithm of this quantity, since it is more normally distributed); and the spectral depolarization ratio, which is the ratio of the particulate depolarization measured in the two channels, $1064 \mathrm{~nm} / 532 \mathrm{~nm}$. The extensive aerosol parameters - aerosol backscattering coefficient, extinction, and optical depth - are not used since these parameters can vary with aerosol amount as well as type.

Measurements are prepared for classification by clearing clouds using a convolution of the measured signal at $532 \mathrm{~nm}$ with a Haar wavelet to enhance edges (Davis et al., 2000), combined with an algorithm to set a flight-by-flight threshold for separating the generally sharper cloud edges from the less pronounced aerosol feature boundaries in each lidar profile. Optional filtering criteria are applied to the HSRL aerosol measurements at this stage. Typing of outliers or noisy points with the aerosol classification algorithm will be less reliable 
than for well-behaved points, but since each measurement is classified independently, the inclusion or exclusion of outliers has no effect on the classification of the remainder of observations, in contrast to global minimization algorithms like $k$-means (MacQueen, 1967). The criteria listed in Table 2 were applied for the creation of the example figures shown in this paper. Generally, the points that fail these criteria have only small contributions to the column optical depth.

The HSRL aerosol classification is performed in two parts. First, specific samples of known aerosol types are combined to make model distributions. Second, the full dataset of HSRL measurements are classified by comparison with these models. The number of classes depends to some extent on the cases where aerosol type is known with high confidence and should not be considered definitive. The choice of classes also reflects a desire for the categories to be physically meaningful and suggest possible aerosol sources; to this end, the basic classes follow the existing literature (Dubovik et al., 2002; Cattrall et al., 2005; Omar et al., 2005). In addition, the number of classes ideally should maximize the information content captured by the class identification. A statistic related to this idea is described in Sect. 4.3. The HSRL aerosol classification described herein uses eight classes, which start with labeled samples of known aerosol types. Section 4.2 describes the eight classes and how the samples were chosen. Thirty samples of a few hundred to a few thousand data points each, in total comprising about $0.30 \%$ of the data, are labeled using a priori knowledge. These samples are combined to estimate multi-normal distributions defined by the 4-by-4 variance-covariance matrix of the four aerosol intensive variables. Distributions are generated from the samples for each of the eight classes after weighting by the sample size so that each sample counts equally within a class. Generalized distances are then calculated for each measurement in the full five-year HSRL record to each of the class distributions, using the Mahalanobis distance metric (Mahalanobis, 1936).

$M_{i j}=\sqrt{\left(\boldsymbol{x}_{i}-\boldsymbol{X}_{j}\right)^{T} \hat{\mathbf{C}}_{j}^{-1}\left(\boldsymbol{x}_{i}-\boldsymbol{X}_{j}\right)}$

$M_{i j}$ is the Mahalanobis distance between measurement $i$ and class $j$, where $\boldsymbol{x}_{i}$ represents the four-dimensional measurement vector for measurement $i, \boldsymbol{X}_{j}$ represents the fourdimensional model vector for class model $j$, and $\hat{\mathbf{C}}_{j}$ represents the variance-covariance matrix for class model $j$.

The Mahalanobis distance is appropriate for quantifying the distance between a point and a distribution, and is therefore a better metric for this application than the Euclidean distance between two points. It assumes the aerosol classes are represented as multi-normal distributions. When the Euclidean distance is used for classification, as is frequently the case in $k$-means clustering (MacQueen, 1967), the measurement points tend to be forced into roughly spherical clusters unless the classes are widely spaced out, since each class is identified by only by a single point. The Mahalanobis
Table 2. Criteria for filtering aerosol measurements for certain figures.

\begin{tabular}{ll}
\hline Aerosol Property & Filter criteria \\
\hline Depolarization at $532 \mathrm{~nm}$ & $0 \leq x \leq 0.6$ \\
Extinction-to-backscatter ratio at $532 \mathrm{~nm}$ & $0 \leq x \leq 100$ \\
Backscatter color ratio, $532 \mathrm{~nm}: 1064 \mathrm{~nm}$ & $0.4 \leq x \leq 4.5$ \\
Ratio of aerosol depolarization ratios, $1064 \mathrm{~nm}: 532 \mathrm{~nm}$ & $0 \leq x \leq 3.5$ \\
\hline
\end{tabular}

distance metric, on the other hand, incorporates more information about the relative shapes and sizes of the classes, including potentially different widths or variances in each dimension and covariance between the variables. The assumption of multi-normal distributions is a much less limiting assumption, and is consistent with the presentation of results by Cattrall et al. (2005). The Mahalanobis distance is frequently the distance metric of choice for Expectation Maximization (EM) clustering (Dempster et al., 1977), which is a generalized form of $k$-means clustering.

After the class distribution models are calculated, the Mahalanobis distance is used to classify aerosol measurements from all HSRL aerosol observations. Points with a Mahalanobis distance greater than a certain threshold from all the classes are considered outliers and are not classified. This threshold (Mahalanobis distance $=4.3$ ) corresponds to the $99.9 \%$ cumulative probability contour of the class distributions, derived by assuming that the Mahalanobis distances belong to a chi-square distribution. That is, $0.1 \%$ of a random sampling of theoretical points belonging to a class would lie at a distance beyond the threshold and would be missed. For points where the Mahalanobis distance to one or more classes is within this threshold, the class identification is inferred from the smallest distance.

Besides providing the most likely class identification for each measurement, the Mahalanobis metric also gives an estimate of the probability for each class. The eight probabilities are normalized to give an estimate of the relative probability for each class. We require the normalized probability to be at least $60 \%$ for an observation to be assigned to a given class. In cases where none of the eight probabilities exceeds $60 \%$ because the point is nearly equidistant from two or more of the nearest classes, the normalized probabilities are recorded, but no class identification is made.

The new classification method described here differs from unsupervised classification schemes like $k$-means (MacQueen, 1967) or expectation maximization clustering (Dempster et al., 1977) primarily in the use of labeled samples. This allows us to incorporate additional knowledge about aerosol type that may be available only in specific cases. This method also has the benefit that new data can be easily classified without causing existing classifications to be greatly altered. The classification is robust with respect to the inclusion or exclusion of outliers, noisy points, 

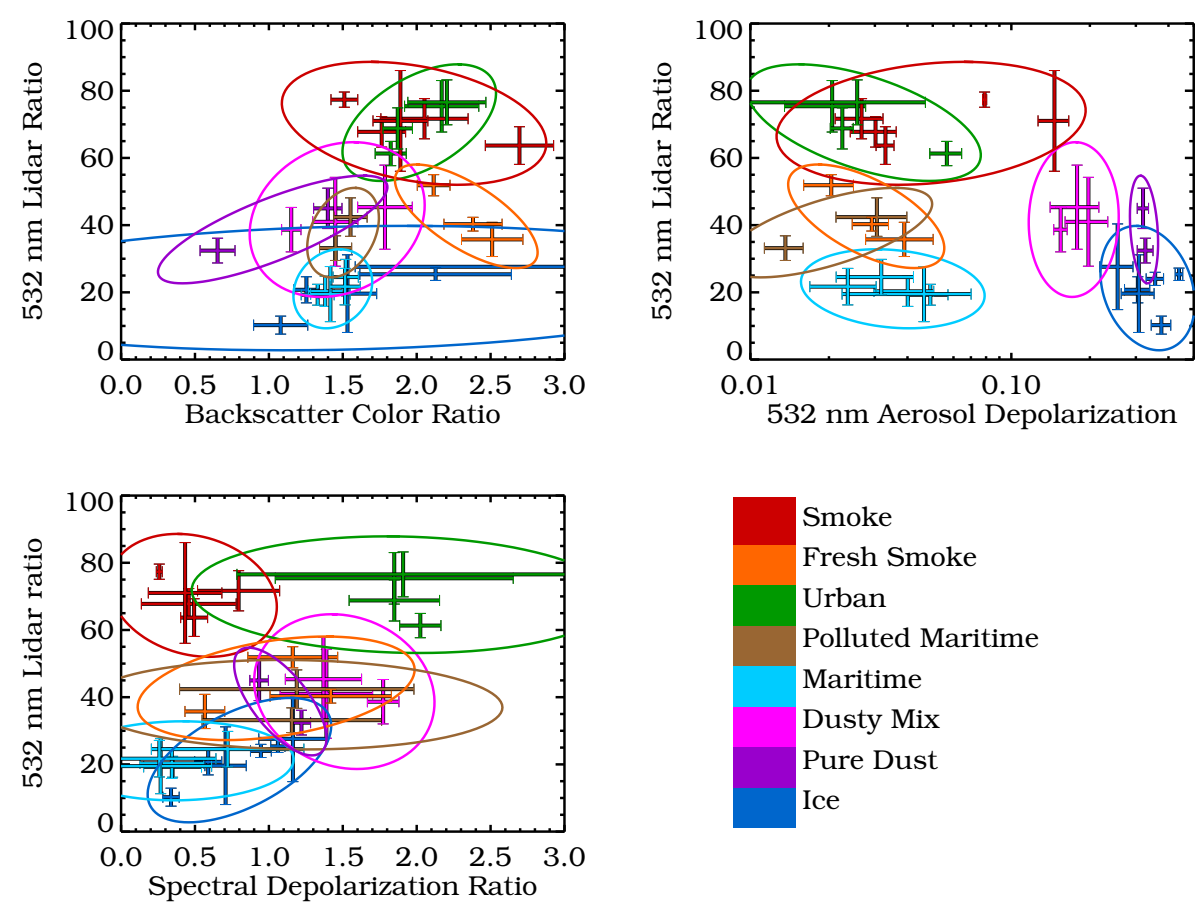

Fig. 4. Illustrates the models used in the aerosol classification algorithm in three projections of a space defined by the four aerosol intensive variables measured by HSRL. Crosshairs indicate data samples of known type as mean and standard deviation of the four variables. The aerosol type models that are based on these samples are indicated by two-sigma ellipses, calculated using the eigenvectors and eigenvalues of the model covariance matrices.

or otherwise unreliable measurements, in the sense that the classification of other points will remain unchanged. Classes can even be added or removed with minimal disruption to the other classes. This is in sharp contrast to unsupervised clustering methods in which any change has global consequences, since those algorithms depend on iterative global minimization of the distance metric.

\subsection{Aerosol types}

The HSRL aerosol classification has eight types and begins with thirty samples of labeled data, between two and six samples for each type. Figure 4 shows the characteristics of the samples in terms of the four intensive variables used for classification. The samples are shown as cross-hairs representing the sample standard deviations in each of the four variables. All the samples of each type are combined to produce variance/covariance matrices which are used later as the model distributions. Two-sigma covariance ellipses for these models are also shown in Fig. 4. The ellipse used to visualize a covariance matrix is determined by its eigenvalues and eigenvectors (see e.g. Rodgers, 2000). The square roots of the eigenvalues are the major and minor axes (doubled in this figure to represent two-sigma variability). These are not necessarily aligned with the variable axes or equal to the standard deviations for each variable, since the covariance terms (off-diagonals) of the variance/covariance matrix are not necessarily zero. The directions of the major and minor axes are given by the eigenvectors.

The eight particulate classes in this analysis were chosen to provide a useful separation of the observations into distinct types. These classes are: ice, pure dust, dusty mix, maritime, polluted maritime, urban, fresh smoke, and smoke. The choice of classes tries to address a balance between too few classes which would cause important distinctions between different observations to be lost, and too many classes which could make it easy to overlook important similarities and prove difficult to interpret. Our choice of eight classes was based on extensive inspection of the HSRL data. The types used in this study reflect the heritage of previous work on classification of lidar measurements (Cattrall et al., 2005; Omar et al., 2005), with some additions that are described herein.

The strategy of using labeled samples to create "seed" aerosol class models to classify all other measurements allows us to incorporate knowledge based on a relatively limited set of observations where the aerosol type is known or easy to infer. Specifically, we incorporate six samples of ice haze (see Sect. 4.2.1) observed during the ARCTAS campaign, identifiable by the signature of fall-streaks in the lidar measurements. Pure dust is represented by two labeled samples. One of these was a plume of Saharan dust tracked by the CALIPSO lidar instrument as it was advected from Africa to the Gulf of Mexico, described by Liu et al. (2008). 
CALIPSO and HSRL observed it simultaneously near Houston, Texas ten days later. The other pure dust labeled sample is from a dust storm on the slope of Pico de Orizaba observed during the MILAGRO field campaign described by de Foy et al. (2011). Three labeled samples of dusty mix include cases of probably locally generated dust with intermediate values of depolarization, including two in the midwestern United States and one near Mexico City that is also discussed by de Foy et al. (2011). Clean air samples in the Caribbean provided most of five labeled samples for the maritime class. Labeling of two samples of polluted marine air from the marine boundary layer in the Gulf of Mexico and near the coast of Virginia was justified by backtrajectory analysis using the online HYSPLIT tool from the NOAA Air Resources Laboratory READY website (Draxler and Rolph, 2012) (http://ready.arl.noaa.gov/HYSPLIT.php) which was used to track the air samples from the marine boundary layer a short time backward to urban areas. Four urban samples are used where the attribution of elevated levels of aerosol optical depth to urban sources is fairly straightforward, for example near Washington DC or, in one case, Mexico City in a region where the WRF-Flexpart model also indicates urban aerosols (de Foy et al., 2011). In the case of smoke (five samples) and fresh smoke (three samples), the plume was observed visually from the B200 or was measured by coincident airborne in situ measurements (Warneke et al., 2010) and/or MODIS images (Saha et al., 2010, see Fig. S7a). Some of the classes, such as pollution, maritime, smoke, and dust, correspond with aerosol types from previous studies (e.g. Dubovik et al., 2002; Omar et al., 2005). Other categories, pure dust, fresh smoke, and polluted maritime, were added based on HSRL measurements, simultaneous observations from the aircraft, and preliminary findings using the fully unsupervised cluster analysis schemes, $k$ means and Expectation Maximization, and will be discussed below. Particular samples were chosen to attempt to provide good coverage of the apparent range of lidar intensive observables for each type, while simultaneously holding back some known samples to judge the success of the classification. Removing or replacing individual samples can affect a small percentage of measurements on the apparent boundaries between classes but does not affect the results overall. We do not have enough labeled samples to perform a statistical assessment of the effect of sample selection; however, the experiment described later in Sect. 4.3 gives a quantitative idea of the amount of error due to points being near the boundaries.

\subsubsection{Ice particles}

Elevated aerosol depolarization values are usually an indication of dust and/or ice. During the ARCTAS campaign, many cases were observed of optically thin ice or ice crystal haze (Saha et al., 2010). These common ice layers have been previously reported extending above $6.5 \mathrm{~km}$ (Greenaway, 1950) and sometimes are precipitating crystals based on evidence of fall streaks in the HSRL lidar data. Hoff (1988) observes similar ice crystal precipitation events that are often obvious in ground-based lidar records although no visible clouds are evident. Curry et al. (1990) point out that although Hoff uses the apt term "ground-based cirrus", these cloud-free ice crystal hazes are neglected in contemporary cloud classification conventions and in radiation transfer and climate calculations. More recently, model parameterizations are available for ice fog (Girard and Blanchet, 2001). However, ice crystal hazes observed by HSRL during ARCTAS were not cleared as clouds in AERONET observations and frequently contribute significantly to AERONET aerosol optical depth. Nearby Total Sky Imager camera images also indicated clear conditions, but Millimeter Cloud Radar consistently indicated cloudy conditions. The likely explanation for these observations is the presence of relatively large particles, but in low concentrations. Large (>1) Ångström exponents observed by AERONET suggest that the particles are smaller than typical cirrus particles. These ice crystal airmasses are not cleared from the HSRL measurements as clouds either, so we need to be able to separate them from aerosol particles.

Ice observed by HSRL during the ARCTAS campaign can have particle depolarization of up to $60 \%$ at $532 \mathrm{~nm}$, which is greater than that associated with pure dust (Sugimoto and Lee, 2006; Liu et al., 2008; Freudenthaler et al., 2009). Mishchenko and Sassen (1998) also indicate depolarization values at $532 \mathrm{~nm}$ up to $50-70 \%$ are possible for ice crystals with effective radius on the order of a micrometer. Since the depolarization of ice crystals is highly variable (e.g. Sassen and Hsueh, 1998) and can be comparable to that of dust, it is difficult to use particle depolarization alone to separate ice and dust (Sakai et al., 2003). Based on our HSRL measurements and from previous ground-based HSRL (e.g. Eloranta, 2005) and Raman lidar (e.g. Whiteman et al., 1992) observations, the lidar ratios for ice are lower than for pure dust, less than 30 sr (Sakai et al., 2003).

Figure 5 shows an example of HSRL measurements acquired over Alaska during the ARCTAS mission. Aerosol depolarization values were elevated at altitudes above $3 \mathrm{~km}$ for much of this period. The very high $(0.5-0.6) 532-\mathrm{nm}$ particulate depolarization values and low $(\sim 20 \mathrm{sr}) 532-\mathrm{nm}$ lidar ratio values around 23.65 UT (23:39) and above $5 \mathrm{~km}$ are associated with ice crystals. At other times and altitudes, it is difficult to use depolarization alone to discriminate ice and dust; however, the higher values of the 532-nm lidar ratio (40-50 sr) strongly suggest that the particles were much more likely to be dust than ice. The spectral ratio of depolarization also appears to help distinguish between ice and dust, as illustrated by the labeled samples in Fig. 4 and by the contrast between low ratio for ice and higher ratio for dust in this example. This case also provides an example indicating the potential for elevated dust layers to act as ice nuclei (Sassen, 2002). 

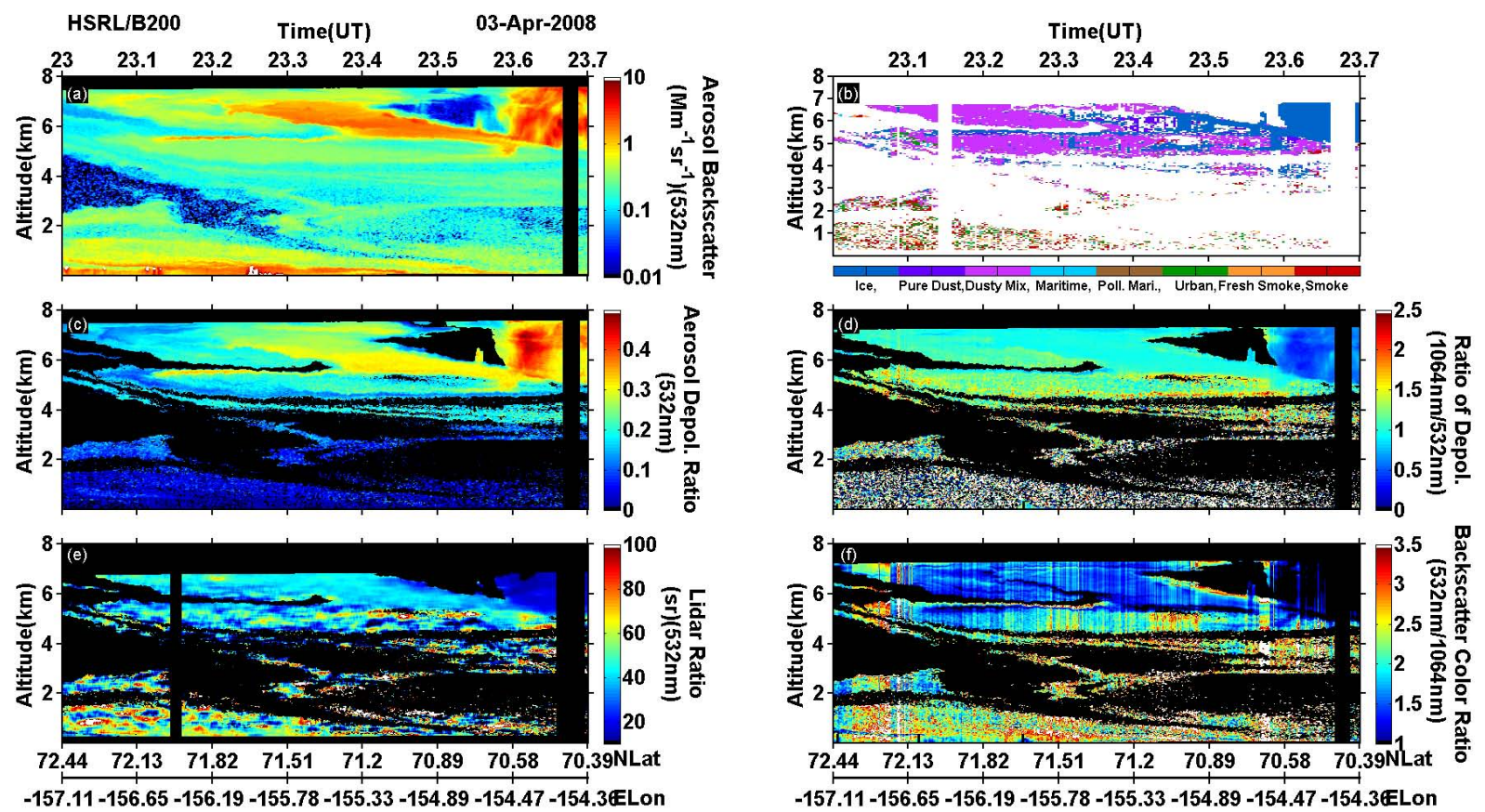

Fig. 5. 3 April 2008 measurements by the NASA Langley airborne HSRL based out of Barrow, Alaska during the ARCTAS campaign. (a) Aerosol backscatter coefficient $(532 \mathrm{~nm})$, (b) aerosol type inferred by the method described in this paper, (c) particle depolarization $(532 \mathrm{~nm}),(\mathbf{d})$ particle depolarization spectral ratio $(1064 / 532 \mathrm{~nm}),(\mathbf{e}) S_{\mathrm{a}}$, the lidar ratio $(532 \mathrm{~nm})$, and (f) aerosol backscatter color ratio $(532 \mathrm{~nm} / 1064 \mathrm{~nm})$. The measurements show an elevated layer made up of both ice crystals, in the region characterized by the largest particle depolarization ratios and smallest lidar ratio, and dust, with somewhat smaller particle depolarization and larger lidar ratio.

\subsubsection{Dust and dusty mix}

Particle depolarization ratios at $532 \mathrm{~nm}$ between about $30 \%$ and $35 \%$ are characteristic of "pure dust" from Asia (Shimizu et al., 2004; Sugimoto and Lee, 2006) or the Sahara desert (Liu et al., 2008; Freudenthaler et al., 2009; Esselborn et al., 2009). Figure 6 shows an example of Saharan dust observed during an HSRL flight on 18 August 2010 between Bermuda and St. Croix, Virgin Islands. The Saharan origin of the dust layer was confirmed using the online HYSPLIT tool from the NOAA Air Resources Laboratory READY website (http://ready.arl.noaa.gov/HYSPLIT.php) (Draxler and Rolph, 2012). Observed values of 532-nm aerosol depolarization for this case are about $33 \%$ and 532-nm lidar ratio values are $49 \pm 9 \mathrm{sr}$. These lidar ratio values are consistent with lidar ratio values of 53-55 \pm 7 given by Tesche et al. (2009b) and also within the range of variability of 38$50 \mathrm{sr}$ observed by Esselborn et al. (2009), both for Saharan dust nearer to the source during SAMUM (Heintzenberg, 2009). Esselborn et al. (2009) show by backtrajectory analysis that their observed variability in lidar ratio is primarily attributable to differences in source regions.

Smaller but still large 532-nm aerosol depolarization values, from about $20 \%$ to $35 \%$, have been often observed by HSRL particularly in the CHAPS and RACORO campaigns (in Oklahoma) and in the MILAGRO campaign (in Mexico), as well as near Houston, Texas, during the TexAQS/GoMACCS mission (Liu et al., 2008). These values of depolarization are consistent with observations of dust mixed with other species (e.g. Heese and Wiegner, 2008) and are identified by our algorithm as a "dusty mix". Various other studies (e.g. Léon et al., 2003; Sugimoto and Lee, 2006; Tesche et al., 2011; Groß et al., 2011; Weinzierl et al., 2011) have attempted to characterize the optical and microphysical properties of case studies of mixtures of dust with other species. In the broad classification methodology presented here, "dusty mix" labels a general category that may include cases of dust mixed with a variety of other species.

Motivating and supporting the idea of having two dust categories with different degrees of depolarization was the observation that the overall distribution of aerosol depolarization from campaigns excluding ARCTAS (that is, excluding ice) shows a long tail of large depolarization values which includes samples known to be dust advected from Africa. Consequently, we also included a second dust category ("Pure dust") to identify such cases. Including it has the practical advantage of aiding the separation of ice and dust. The depolarization values of the optically thin ice observed during the ARCTAS campaign can be comparable to that of pure dust, making it is difficult to use particle depolarization alone to separate ice and dust. As described above, the lidar ratio tends to be smaller for ice than for dust, but the difference 

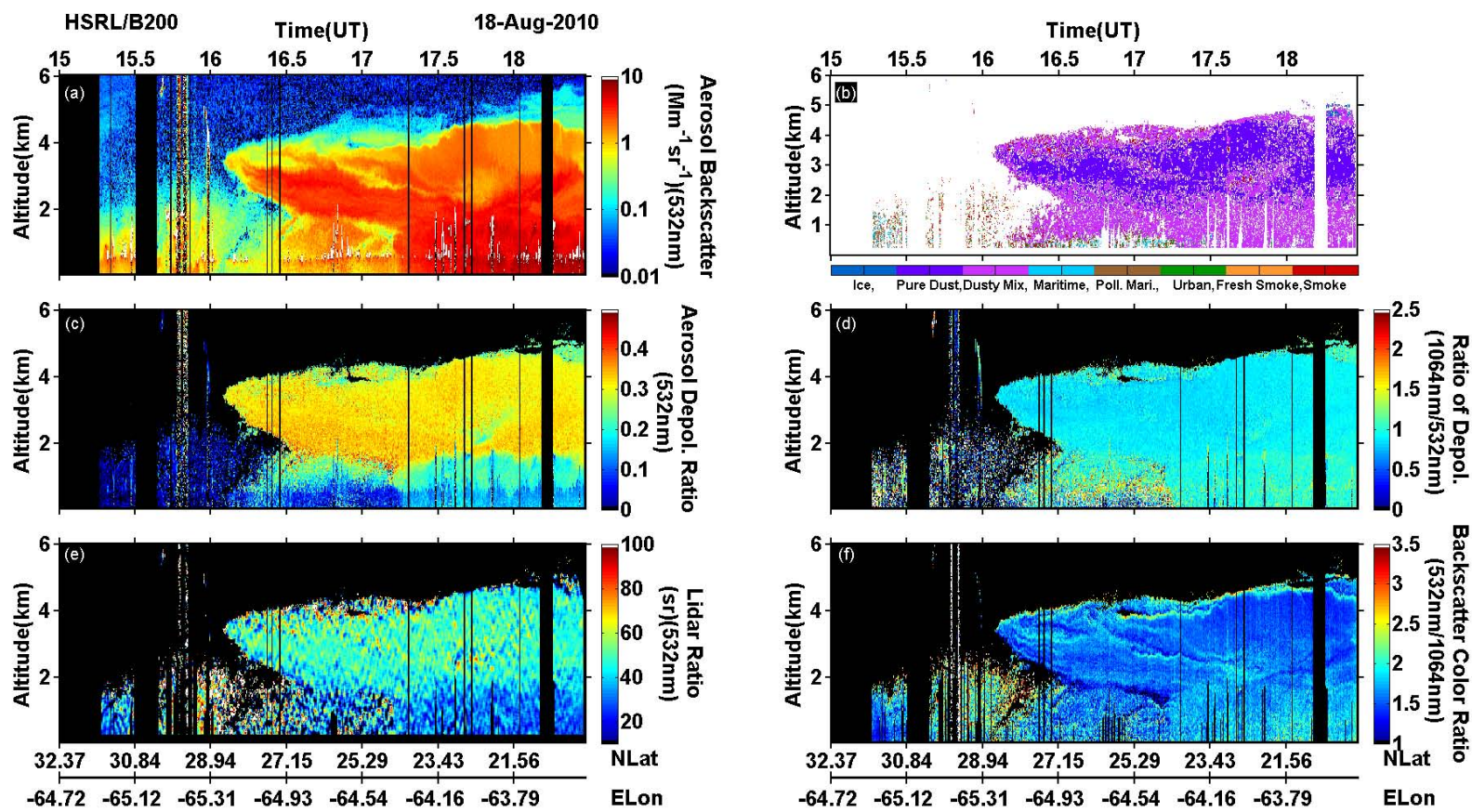

Fig. 6. 18 August 2010 airborne HSRL measurements and aerosol classification for a Saharan dust plume observed on a flight between Bermuda and St. Croix in the US Virgin Islands. (a) Aerosol backscatter coefficient $(532 \mathrm{~nm})$, (b) aerosol type inferred by the method described in this paper, (c) aerosol depolarization $(532 \mathrm{~nm})$, (d) aerosol depolarization spectral ratio $(1064 / 532 \mathrm{~nm})$, (e) $S_{\mathrm{a}}$, the lidar ratio $(532 \mathrm{~nm})$, and (f) aerosol backscatter color ratio $(532 \mathrm{~nm} / 1064 \mathrm{~nm})$.

is subtle enough that the separation of types is more reliable when dust is represented as two categories. This is due to the fact that ice can be more "similar" to pure dust than pure dust is to the remainder of the dust observations, where similarity is judged as distance in the four-dimensional space defined by the four measured variables. Even with two categories for dust, it is still somewhat difficult to separate ice from dust in certain cases. Misclassified cases are often easy to detect because the ambient temperatures obtained from the NASA Global Modeling and Assimilation Office (GMAO) are well above $0^{\circ} \mathrm{C}$. Consequently, a simple temperature-based correction is included in the results shown here; any point categorized as ice but having a temperature above $0{ }^{\circ} \mathrm{C}$ is reassigned to dust (this is a very conservative cutoff, which potentially can leave some cases incorrectly categorized as ice).

\subsubsection{Maritime and polluted maritime}

Maritime aerosols were observed extensively during HSRL observations over the Caribbean Sea during several flights in 2008 and 2010. These aerosols were characterized with low 532-nm lidar ratios (15-25 sr), low 532-nm particulate depolarization $(<10 \%)$, and low backscatter color and depolarization spectral ratios. The polluted maritime classification is generally seen over water or just inland on the Gulf Coast between Houston and Veracruz during the MILAGRO campaign (March 2006) and over the Atlantic Ocean east of Virginia during several campaigns. It was also found extensively in the Gulf of Mexico near the location of the BP Deepwater Horizon oil spill on flights in May and July 2010 (see example in Ottaviani et al., 2012, Fig. 7). The lidar ratio at $532 \mathrm{~nm}$ for this class is about $35-45 \mathrm{sr}$, intermediate between the maritime and pollution classes, which is consistent with observations by Müller et al. (2007a) of polluted marine air over the Maldives during the monsoon season. In our polluted maritime class, backscatter color ratio and spectral ratio of aerosol depolarization are also intermediate between the maritime and pollution classes. It is a small category that contains about $3 \%$ of all the HSRL observations. Most of the fully automated clustering trials did not distinguish between this type and clean maritime air; however, an experimental run of unsupervised expectation maximization clustering with eleven classes generated a cluster like this. Supporting the decision to include the class, it was found that many of these cases would otherwise be labeled an incoherent mix of pollution, smoke and maritime.

\subsubsection{Urban and biomass burning}

Urban and biomass burning aerosols typically have relatively small, spherical particles that produce low depolarization, high backscatter color ratios, and high 532-nm lidar ratios (Cattrall et al., 2005; Müller et al., 2007a). The similarities 

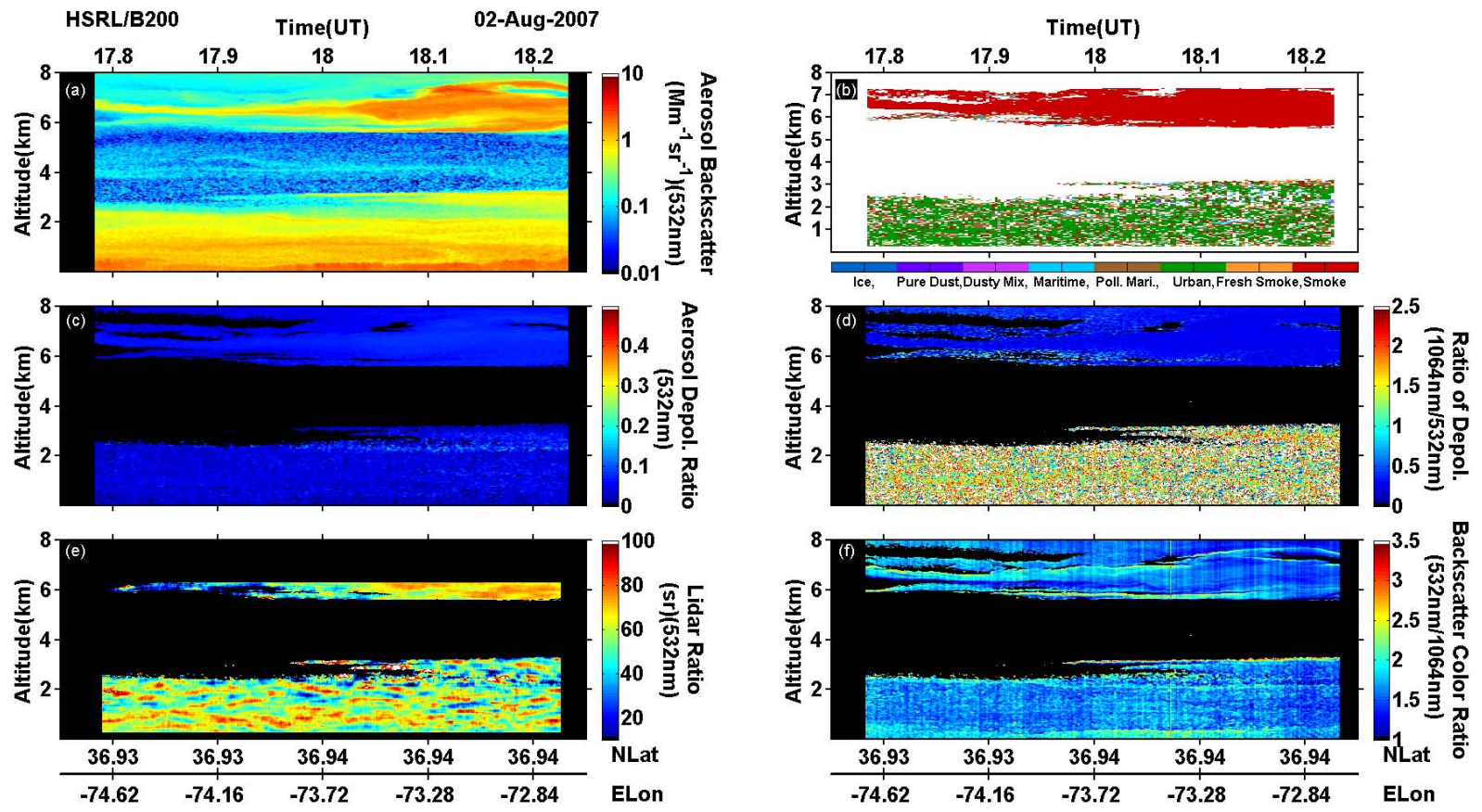

Fig. 7. A B200 flight on the East coast on 2 August 2007 illustrating a smoke layer advected from fires in the northwestern United States and Canada, overlying mostly pollution aerosol from cities on the eastern seaboard. (a) Aerosol backscatter coefficient (532 nm), (b) aerosol type inferred by the method described in this paper, (c) aerosol depolarization $(532 \mathrm{~nm})$, (d) aerosol depolarization spectral ratio $(1064 / 532 \mathrm{~nm})$, (e) $S_{\text {a }}$, the lidar ratio $(532 \mathrm{~nm})$, and (f) aerosol backscatter color ratio $(532 \mathrm{~nm} / 1064 \mathrm{~nm})$. Note the contrast in spectral depolarization ratio between the two aerosol layers.

in the physical characteristics and the resulting optical properties make these types difficult to distinguish. Müller et al. (2007a) have shown that urban and smoke aerosols can be distinguished using the wavelength dependence of the lidar ratio $(355-532 \mathrm{~nm})$ computed from ground-based Raman lidar measurements. Noh et al. (2009) observed only a slight difference in lidar ratio at these two wavelengths for smoke and pollution events in Korea, for which carbon particle analyzer data were also available, but found somewhat more variation in retrieved single scattering albedo (SSA). Russell et al. (2010) indicate that absorption Ångström exponents (AAE) derived from AERONET are strongly correlated with aerosol type, but display some ambiguity between urban-industrial aerosol and biomass burning aerosol. They demonstrate that multi-dimensional analysis consisting of the combination of AAE and extinction Ångström exponent (EAE), for example, shows potential to more fully resolve these types. The depolarization spectral ratio measurements acquired by HSRL also appear to confer some ability to discriminate among these and other aerosol types. The HSRL measurements from a flight on 2 August 2007 over the Atlantic Ocean east of Virginia shown in Fig. 7 illustrate the significant differences in the depolarization spectral ratio, despite the fact that the aerosol depolarization values are small. The aerosols below $3 \mathrm{~km}$ are typical of the urban aerosols seen over the eastern US during summer. The aerosols in the elevated layer above $5 \mathrm{~km}$ are smoke from fires in the northwestern US or southwestern Canada, as determined using the online HYSPLIT tool (Draxler and Rolph, 2012). The elevated layer of smoke has slightly higher lidar ratio at $532 \mathrm{~nm}(70-80 \mathrm{sr})$ than the urban aerosols $(50-$ $70 \mathrm{sr}$ ), consistent with previous Raman lidar measurements of smoke (Wandinger et al., 2002). The elevated smoke layer also has slightly higher particulate depolarization at $532 \mathrm{~nm}$ $(8-10 \%)$ than the lower layer of urban aerosols; this observation of smoke particulate depolarization is consistent with other lidar measurements of long-range smoke transport (Fiebig et al., 2002; Murayama et al., 2004). Although there have been few multiple-wavelength lidar particulate depolarization measurements of these aerosols, there have been efforts to use such measurements to help identify and classify polar stratospheric clouds (Toon et al., 2000), examine Saharan dust characteristics (Freudenthaler et al., 2009; Groß et al., 2011), and infer Angstrom exponents for dust (Sugimoto and Lee, 2006). Somekawa et al. (2008) and Veselovskii et al. (2010) show that multiple wavelength depolarization measurements may be used to infer some particle properties such as size. 

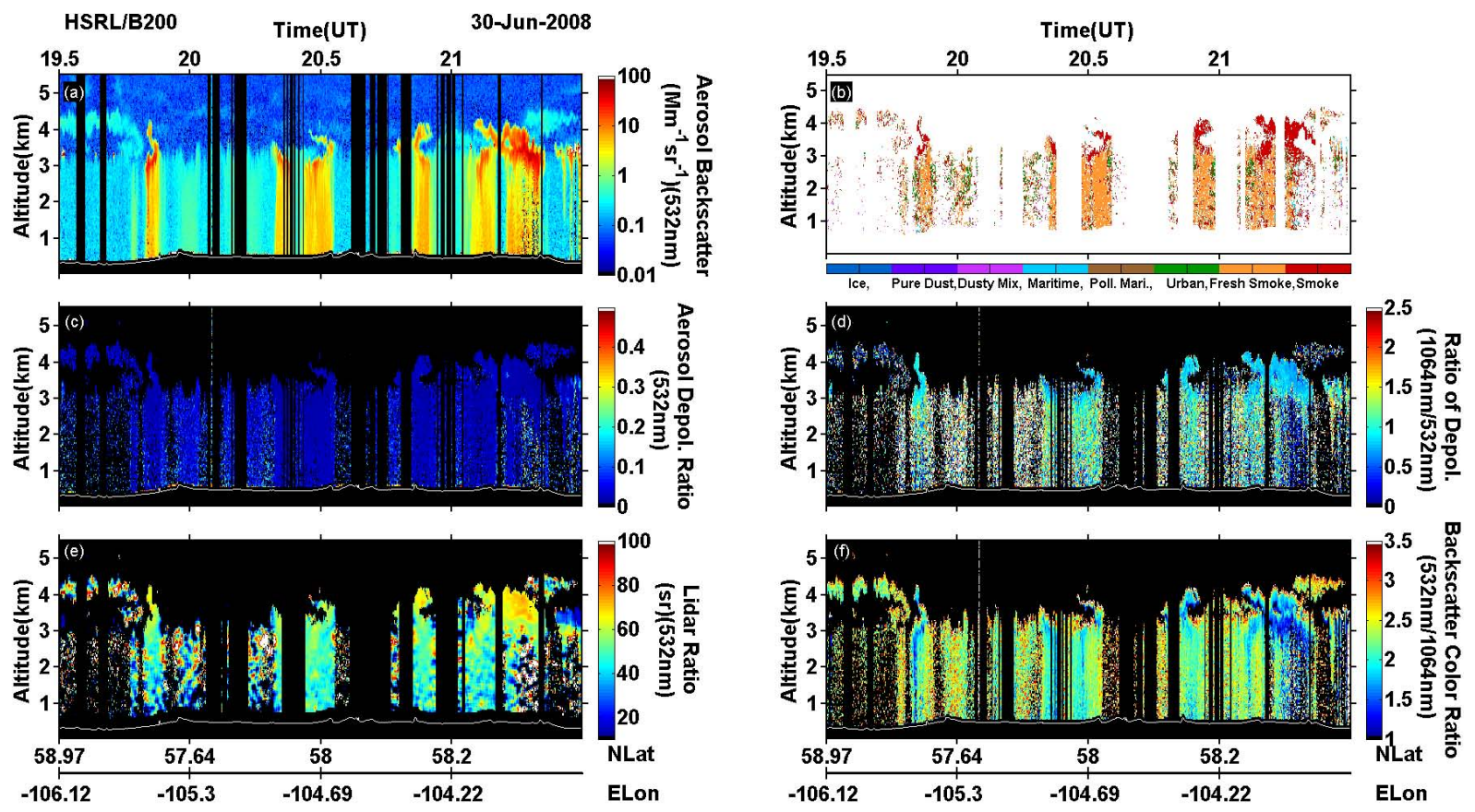

Fig. 8. NASA Langley airborne HSRL observations and aerosol classification are shown for a portion of a flight on 30 June 2008 over northern Alberta, Canada. Multiple passes over a fresh smoke plume are evident. (a) Aerosol backscatter coefficient (532 nm), (b) aerosol type inferred by the method described in this paper, (c) aerosol depolarization $(532 \mathrm{~nm})$, (d) aerosol depolarization spectral ratio $(1064 / 532 \mathrm{~nm}),(\mathbf{e}) S_{\mathrm{a}}$, the lidar ratio $(532 \mathrm{~nm})$, and (f) aerosol backscatter color ratio $(532 \mathrm{~nm} / 1064 \mathrm{~nm})$.

\subsubsection{Fresh smoke}

The category "Fresh Smoke" was included based on observations of visible fresh smoke plumes with very different aerosol intensive parameters measured by HSRL. For example, samples of fresh smoke in the boundary layer observed on 30 June and 2 July 2008 during ARCTAS had a significantly smaller lidar ratio at $532 \mathrm{~nm}(30-60 \mathrm{sr})$ than the advected smoke $(60-80 \mathrm{sr})$ from Siberian forest fires seen on other dates during the same campaign, such as 78 July 2008. Figure 8 shows an example of HSRL measurements for the smoke plume observed over northern Alberta on 30 June 2008. Fresh smoke plumes observed over fires in North Carolina in March 2008 also had similar smaller 532-nm lidar ratios of approximately 50-55 sr. In both of these cases, the smoke was only a few hours old and observations were within $10-100 \mathrm{~km}$ of the fires. The lower value of lidar ratios for fresh smoke as compared to aged smoke are consistent with ground-based Raman lidar measurements over Spain (Alados-Arboledas et al., 2011) and Greece (Amiridis et al., 2009). Although these studies and Müller et al. (2007b) indicate that particle size is likely to increase with age, there is considerable spread in the observed backscatter Ångström exponents (or color ratios). HSRL measurements of backscatter color ratio indicate larger values (smaller particles) for fresh smoke than aged smoke on average, but without a clear separation (compare Wandinger et al., 2002; Amiridis et al., 2009; Alados-Arboledas et al., 2011). The HSRL measurements also showed that the aerosol depolarization ratio at $532 \mathrm{~nm}$ for fresh smoke was typically low $(<2-5 \%)$ and also typically lower than for more aged smoke (3-8\%). This result is consistent with the magnitude and variability of previous lidar measurements of smoke (Sassen, 2000).

\subsection{Sensitivity analysis}

As described above, the distinctions in the HSRL measurements of these four aerosol intensive parameters support the choices of these classes. The Wilks' overall lambda statistic (Hill and Lewicki, 2007) gives some indication of how well the data lend themselves to separation into classes. Wilks' lambda varies from 0 to 1 , with smaller values indicating significant difference between groups and larger values indicating that the group means are the same. For the HSRL data classified into eight classes as described above, Wilks' lambda is 0.083 ; if outliers are also included, the value is 0.137 .

Wilks' partial lambda can be used to indicate the relative discriminatory power of each intensive parameter. This value is the ratio of Wilks' lambda calculated with and without a given variable. Again, smaller values indicate more importance, allowing the values to be ranked in order. Wilks' partial lambda is smallest for the $532 \mathrm{~nm}$ depolarization, 0.47 , 
Table 3. Median uncertainties for intensive parameters used in Monte Carlo cross-classification analysis.

\begin{tabular}{ll}
\hline Intensive variable & Median uncertainty for HSRL measurements included in aerosol classification study \\
\hline Aerosol depolarization at $532 \mathrm{~nm}$ & 0.0074 \\
Lidar ratio at $532 \mathrm{~nm}$ & $12.1 \mathrm{sr}$ \\
Backscatter spectral ratio $(532 / 1064 \mathrm{~nm})$ & 0.128 (propagated from backscatter uncertainties assuming independence) \\
Depolarization spectral ratio $(1064 / 532 \mathrm{~nm})$ & 0.774 (propagated from aerosol depolarization uncertainties) \\
\hline
\end{tabular}

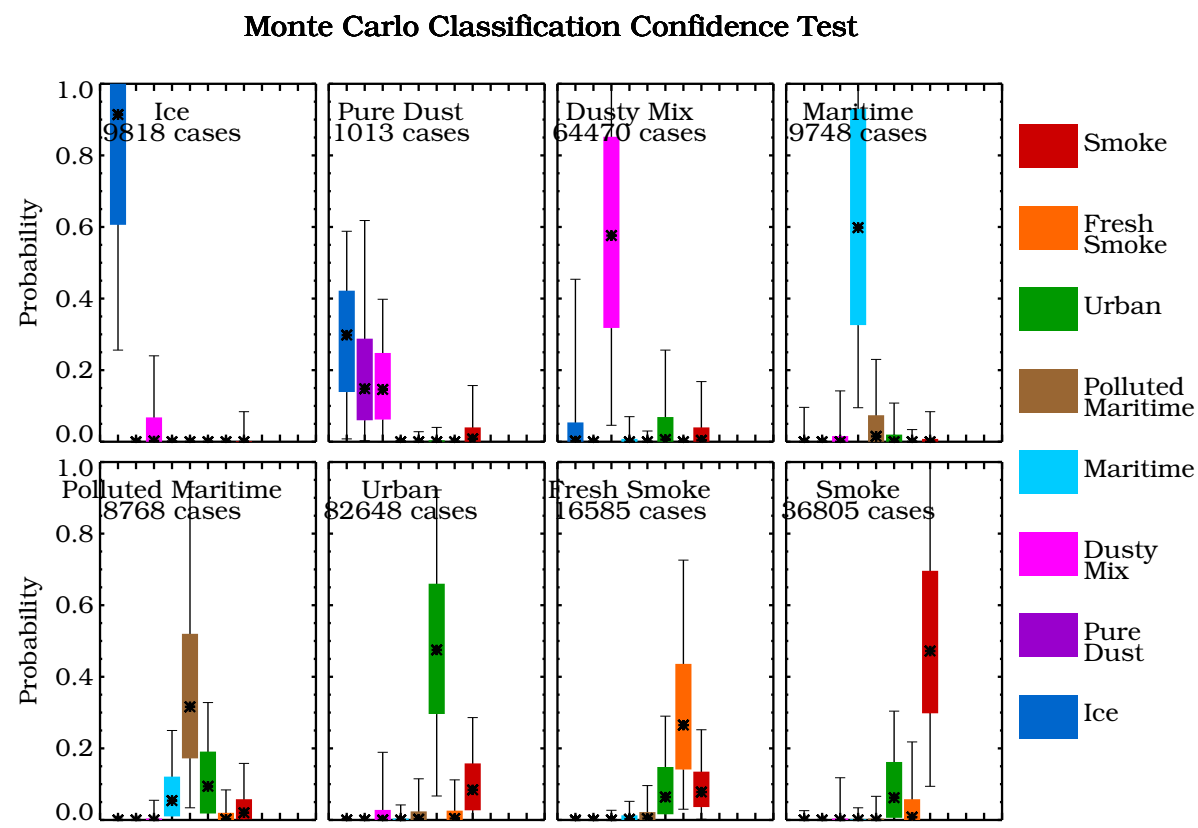

Fig. 9. Shows the results of a Monte Carlo experiment in which a cloud of 500 perturbed measurements for each point is classified and the classification is compared to the classification of the original unperturbed point. The first panel shows the results for all points that were originally classified ice; the bins along the x-axis show the statistics of how the perturbed points were classified, color coded as shown. The second panel is for pure dust, etc., as labeled. Perturbed ice measurements are still ice; perturbed pure dust are split among pure dust, dusty mix and ice; dusty mix and maritime are easy to classify. Smoke (especially fresh smoke) is difficult to separate from pollution.

indicating that this variable has the most weight in the classification. This is followed closely by depolarization spectral ratio and lidar ratio, with partial lambda values of 0.54 for each. The backscatter color ratio has the least discriminatory power, with a partial lambda of 0.79 .

Some classes are easier to distinguish than others. The potential for misclassification is illustrated in Fig. 9, which shows the results of a Monte Carlo study wherein simulated observations are made by perturbing each point 500 times within the measurement uncertainties of the four intensive variables; then these simulated points are themselves classified. Table 3 shows the median measurement uncertainties for these variables. For this test, the uncertainty values for the two spectral ratios are propagated from the single-channel values with an assumption of independence between the channels, so the uncertainties used here are larger (more conservative) than the true measurement uncertainty. Figure 9 illustrates the probability that perturbing each measurement within the uncertainties will change the inferred classification. This is one way to understand the relative difficulty in separating various pairs of classes. For example, the maritime class is quite easy to infer. Even after perturbation, most of the Monte Carlo points are still classified as maritime, with very small percentages cross-classified into the other categories. Not surprisingly, smoke and urban are harder to separate, and between about $5 \%$ and $15 \%$ of the perturbed points are cross-classified. Polluted maritime has cross-classification into the related categories of maritime and urban. The pure dust category and the "fresh smoke" category derived from smoke in the boundary layer have the most cross-classifications with other categories.

The Monte Carlo study quantifies only one possible kind of error in this analysis, essentially the potential for misclassification due to measurement errors. This experiment does 
$532 \mathrm{~nm}$ Aerosol Depolarization

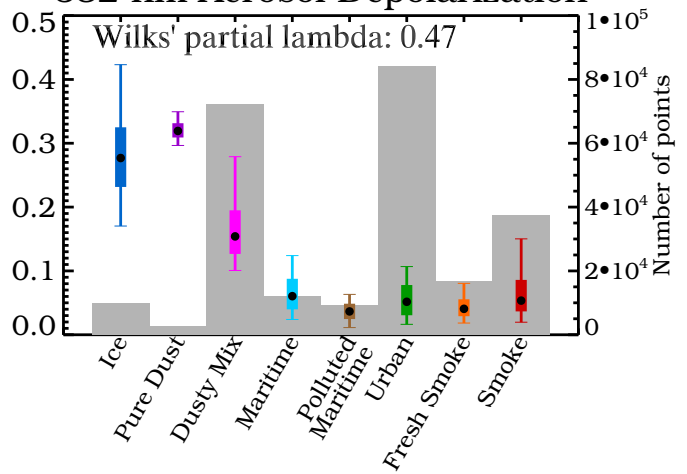

Backscatter Color Ratio

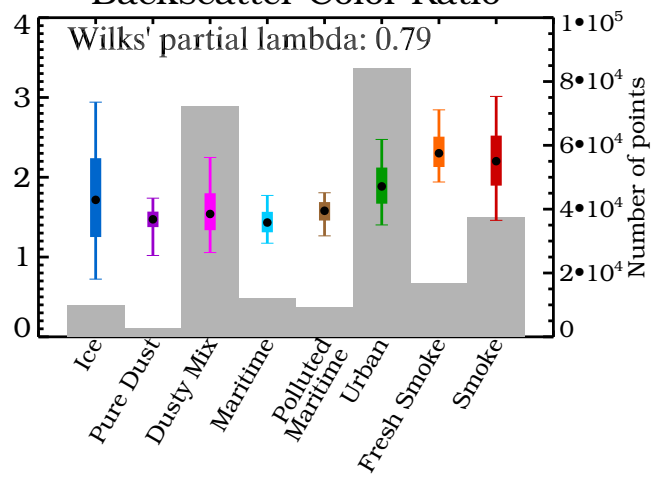

532 nm Lidar Ratio

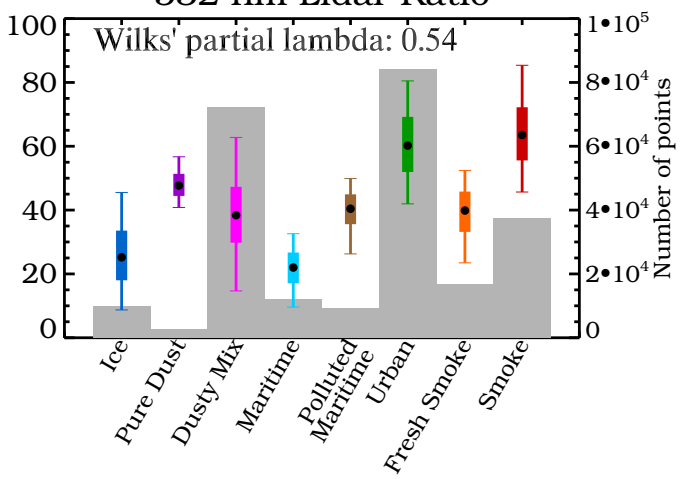

Depolarization Spectral Ratio

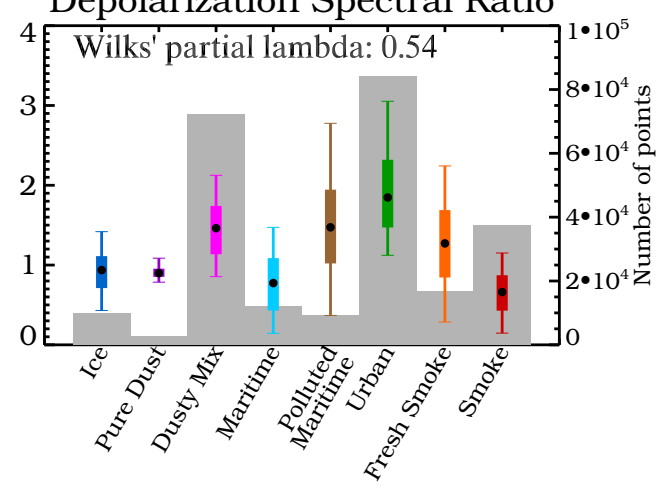

Fig. 10. Colored bars and whiskers show the median (dot), 25-75 percentile (box) and 5-95 percentile (whisker) of the four aerosol intensive parameters, after classifying all HSRL data from all missions into eight types. The gray bars represent the number of points in each class, using the right-hand data axis. Also shown is the Wilks' partial lambda statistic illustrating the relative importance of each of the four variables in the classification. For the case of aerosol depolarization at $532 \mathrm{~nm}$, Wilks' partial lambda is calculated on the natural log of the variable. In this figure (and throughout), the backscatter color ratio is defined as $532 \mathrm{~nm} / 1064 \mathrm{~nm}$, while the depolarization spectral ratio is defined as $1064 \mathrm{~nm} / 532 \mathrm{~nm}$.

not address potential errors from the choice of classes or labeled samples or the assumption that multi-normal distributions are adequate to represent the classes. These types of potential systematic errors are of course difficult to quantify. Further confidence in the results can be gained by comparisons with other data sets, both comparisons with the properties of aerosol types already presented in the literature, and more specific comparisons between coincident measurements with aerosol in situ composition instruments. These comparisons are begun in the next section and carried forward in a future paper (Ferrare et al., 2012). Additional research on comparisons with aerosol in situ instruments and models is ongoing.

\section{Results of the classification}

The ranges of the intensive parameters applicable to each of the aerosol classes are displayed in Fig. 10, as median, middle $50 \%$ (boxes) and middle $90 \%$ (whiskers). Also shown are gray bars representing the number of observations of these various aerosol types. The panels are also annotated with the Wilks' partial lambda statistic, described above. This statistic reflects the relative spread of the measurements compared to their standard deviations, and quantifies the relative power of each variable in discriminating the classes, with smaller values indicating more discriminatory power. Figures 11 and 12 also show the results displayed as a series of two-dimensional histograms. Points are color coded by the aerosol classification derived from this study and with the color saturation for each hue corresponding to point density. Less populated bins are not shown; the figures show approximately $50 \%$ of the points in each class. Figure 11 also shows the aerosol intensive properties from some other lidar measurements (Müller et al., 2007a) and derived from ground-based AERONET observations of aerosol properties (Cattrall et al., 2005; Omar et al., 2005) from existing literature. There is general qualitative agreement showing, for example, that dust and maritime aerosols typically have lower lidar ratios and backscatter color ratios, and smoke and urban type aerosols have higher lidar ratios and backscatter color ratios. Figure 11 also clearly shows that there can be considerable spread in these observations for aerosols observed in 


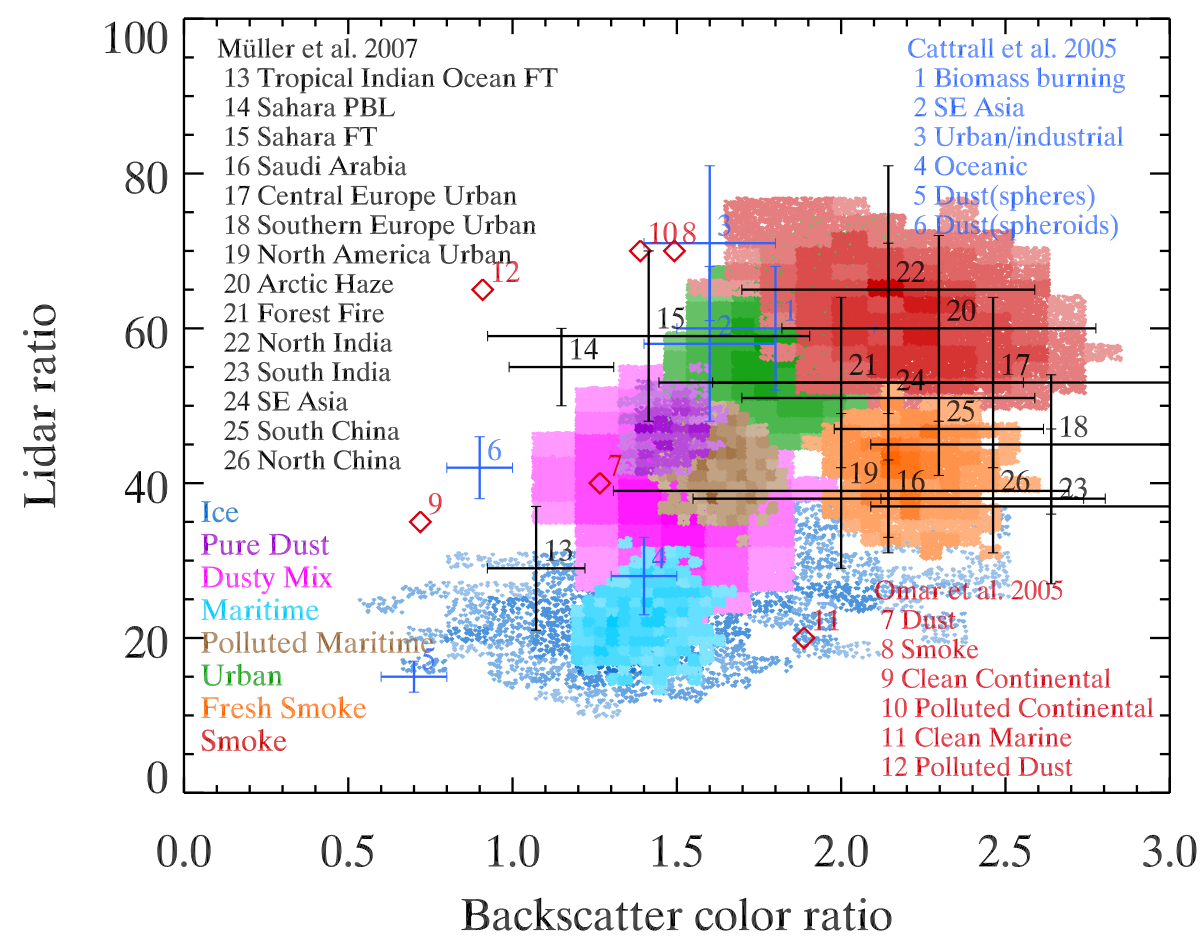

Fig. 11. The results of the classification of HSRL measurements are shown here, projected onto a two-dimensional subset of the four dimensional space. HSRL measurements are color coded by inferred aerosol type, with the saturation in each hue indicating relative population density. Points are shown for the most populous bins such that about half of the population of each cluster is represented. Also indicated in this figure are the aerosol types identified by Cattrall et al. (2005), Omar et al. (2005), and Müller et al. (2007a). (Some of these variables have been inverted to conform to the axes chosen here).

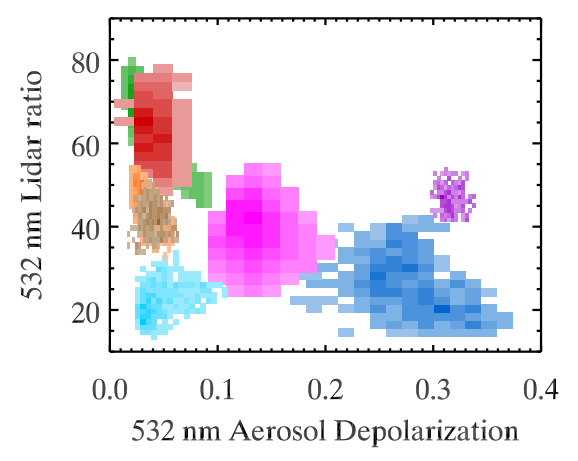

Ice Pure Dust Dusty Mix Maritime

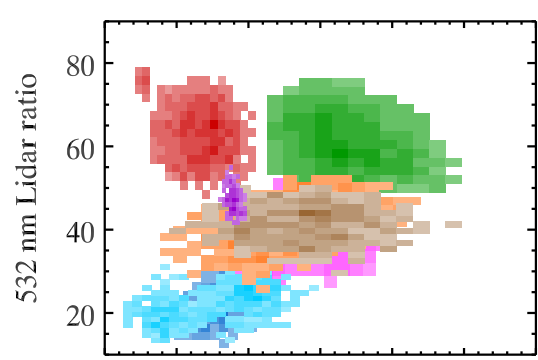

$\begin{array}{lllllll}0.0 & 0.5 & 1.0 & 1.5 & 2.0 & 2.5 & 3.0\end{array}$

Spectral Depolarization Ratio $(1064 \mathrm{~nm} / 532 \mathrm{~nm})$

Polluted

Maritime Urban Fresh Smoke Smoke

Fig. 12. Similar to Fig. 11, but showing two-dimensional projections that include the other two aerosol intensive variables that were used for classification. In this figure, the bins are shown as solid boxes; individual points within the bins are not displayed.

different locations. This figure shows that using lidar ratio and backscatter ratio alone would be insufficient to classify all these aerosol types, as there can be considerable overlap among some of these classes. However, Fig. 12, which shows the additional variables used in the current scheme, indicates that aerosol depolarization and spectral depolarization ratio can be used to distinguish these types. As seen in the figure, the spectral depolarization ratio helps especially in distinguishing ice from dust and smoke from pollution.

Examples of the results of the classifications for some of the observed aerosol types described earlier are shown in Figs. 5b (ice and dust), 6b (dust), $7 \mathrm{~b}$ (smoke and urban) and $8 \mathrm{~b}$ (fresh smoke). Figure 5 shows the separation of ice and dust in the upper troposphere over Alaska, due primarily 
to the low values of lidar ratio (20-30 sr) and much higher values of 532-nm depolarization $(>0.4)$ associated with ice. Figure 6 shows the presence of pure dust associated with Saharan dust transported over the western Atlantic Ocean. The identification of pure dust was driven primarily by the aerosol depolarization values at $532 \mathrm{~nm}$ of $0.3-0.35$ located near the center of the layer. Around the periphery, where the 532-nm aerosol depolarization was below about 0.3 and the aerosols were likely mixed with other types, the classification was a dusty mix. Figure 7 shows the classification of the elevated smoke layer above the urban aerosols for the flight over the eastern US on 2 August 2007. Here, separation between smoke and urban was driven by the differences in spectral depolarization (lower for smoke) and 532-nm depolarization (higher for smoke). Figure 8 shows the classification of fresh smoke when the B200 flew over fires in northern Saskatchewan, Canada. Fresh smoke was classified based on the lower values of the lidar ratio $(40-50 \mathrm{sr})$ combined with a lack of aerosol depolarization at $532 \mathrm{~nm}$. Figure 13 shows the results of the classification for the HSRL measurements acquired over Mexico City and shown in Fig. 2. The classification indicates urban aerosols when the B200 flew over the western part of the city between about 17.7517.80 UT (17:45-17:48), and indicates a dusty mix when the B200 flew over the eastern part of the city between 17.6817.75 UT (17:40-17:45). As described earlier, the classification of dusty mix vs. urban was due to variations in the lidar ratio and depolarization at $532 \mathrm{~nm}$ over these locations. Also visible in Fig. 13 is an elevated fresh smoke plume at about $4.5 \mathrm{~km}$ over the western part of the city. The identification of fresh smoke here is consistent with WRF-Flexpart (de Foy et al., 2011, Fig. 8). Figure 13 also illustrates an example of the apportionment of AOD among these types.

Figure 14 illustrates the apportionment of AOD for two cases, discussed previously, having a significant dust component. These cases are the flight on 13 March 2006 over Mexico City (as in Figs. 2 and 13) and the Caribbean flight of 18 August 2010 (Fig. 6). The black line shown in Fig. 14 shows the optical depth due to dust computed using the method of Sugimoto and Lee (2006), which assumes that the dust mixing ratio scales linearly with the aerosol depolarization. Figure 14b and d illustrate a comparison of this computed value of dust partial optical depth to the total AOD associated with the two types "pure dust" and "dusty mix" in our classification, for the entire MILAGRO (14b)and Caribbean 2010 campaigns (14d). In general, the two estimates are in agreement, but the sum of the AOD for the two classes exceeds the dust partial optical depth as computed using the Sugimoto and Lee (2006) algorithm. This is not surprising since most of the aerosol in the "dusty mix" type has depolarization less than the assumed depolarization value for pure dust in that calculation. In the MILAGRO campaign, the dust is mixed with urban and smoke aerosol, while in the Caribbean campaign it is mixed with maritime aerosol.

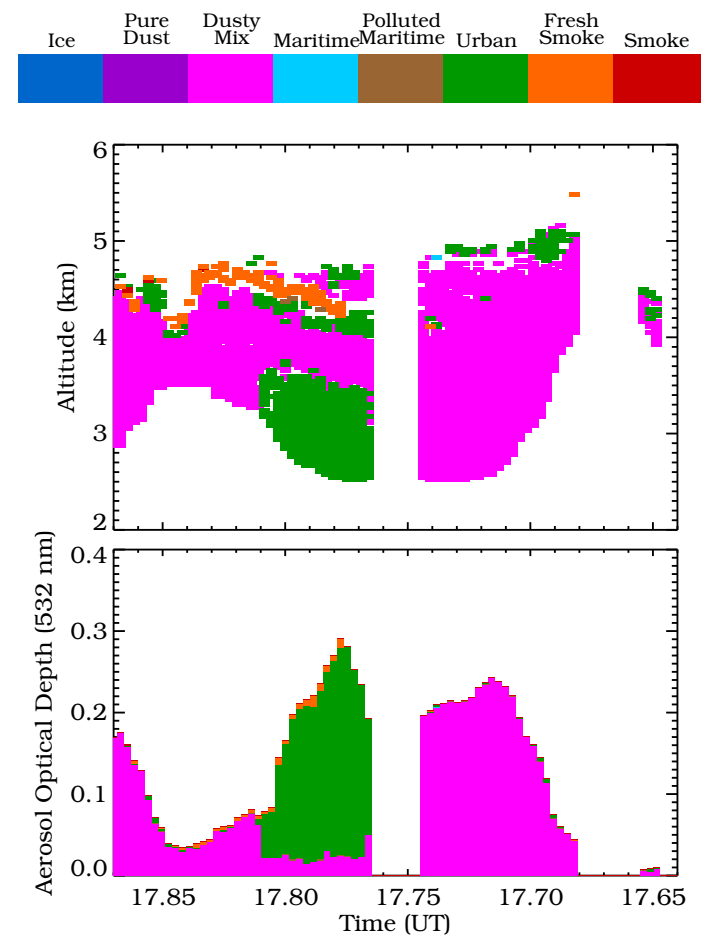

Fig. 13. Results of the aerosol classification for the HSRL measurements shown in Fig. 2. The top panel shows aerosol type along the flight track as a function of altitude. Urban aerosols dominate in the western part of Mexico City while dusty aerosol dominates elsewhere. An elevated smoke plume is also visible around $4.5 \mathrm{~km}$ altitude in the west part. The bottom panel illustrates the apportioning of aerosol optical depth among the types for this flight segment as stacked histogram bars.

The HSRL measurements acquired during the spring and summer ARCTAS campaigns have been used to apportion the vertical profile of aerosol extinction to aerosol types. Figure 15 reflects the median aerosol extinction profiles measured during the spring and summer ARCTAS campaigns, apportioned by aerosol type. B200 flights were conducted in April 2008 over northern Alaska during the spring ARCTAS campaign ("ARCTAS 1") and over northern Alberta, northern Saskatchewan, and the southern Northwest Territories Canada in June and July 2008 during the summer ARCTAS campaign ("ARCTAS 2"). Figure 15 shows that, during ARCTAS 1, ice was more pronounced in the mid troposphere between $2-5 \mathrm{~km}$, and in the upper troposphere between $6-7 \mathrm{~km}$ during ARCTAS 2. The fraction of aerosol extinction contributed by dust was relatively constant with altitude during ARCTAS 1 and decreased with altitude during ARCTAS 2. During ARCTAS 1, portions of several B200 flights were conducted over water and the Arctic Ocean, which likely explains the significant fraction of maritime extinction observed near the surface. In contrast, very little maritime aerosol was observed during ARCTAS 2, which is not surprising given that the flights were conducted inland 

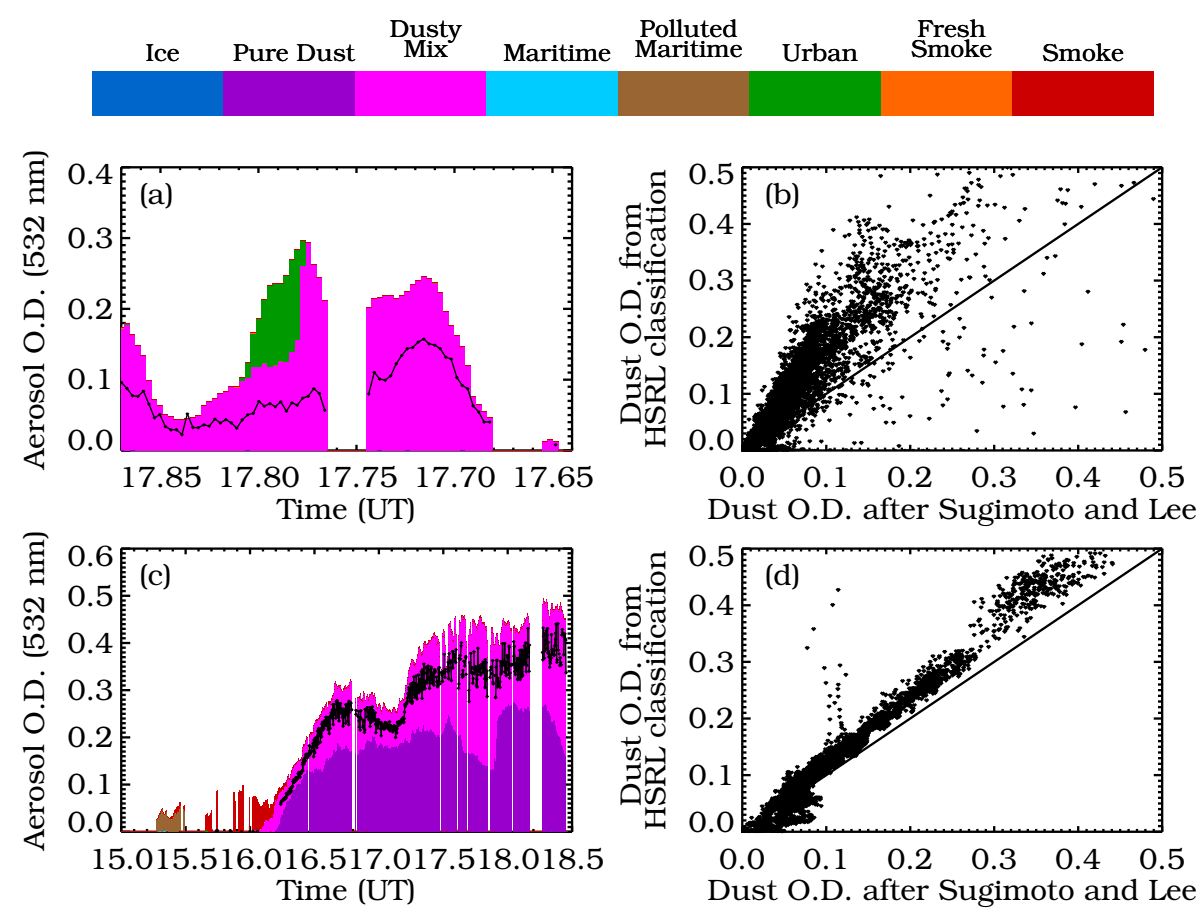

Fig. 14. Time series of AOD apportioned to aerosol types for the flight segments on 13 March 2006 during MILAGRO (a) and for 18 August 2010 during the Caribbean 2010 field mission (c). The black trace on these panels shows the optical depth fraction attributed to dust computed using the method of Sugimoto and Lee (2006). The Sugimoto and Lee (2006) dust partial optical depth and the sum of the AOD for "Pure Dust" plus "Dusty Mix" are compared for the entire MILAGRO field campaign (b) and for the 2010 Caribbean campaign (d).
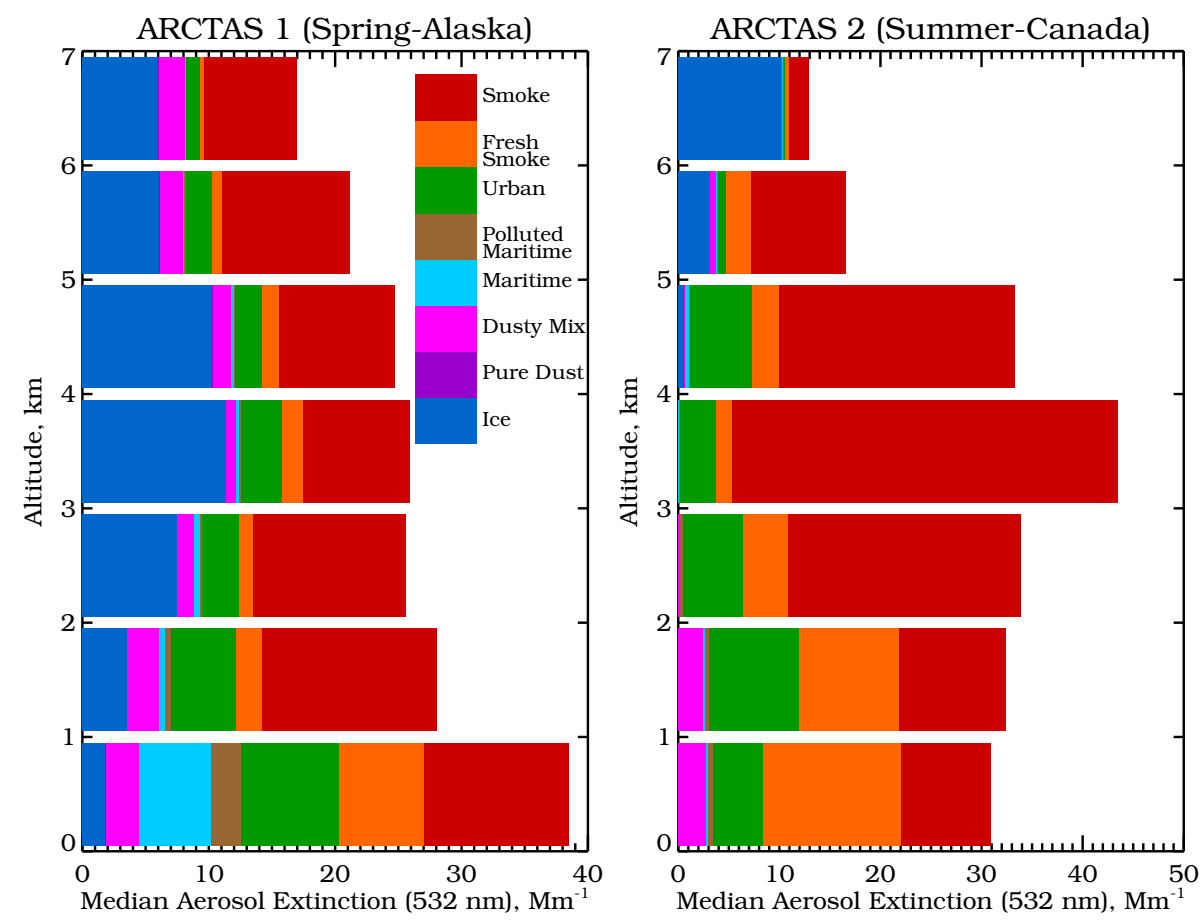

Fig. 15. Aerosol extinction as a function of altitude is shown here apportioned among the eight aerosol types for the ARCTAS spring and summer campaigns. 

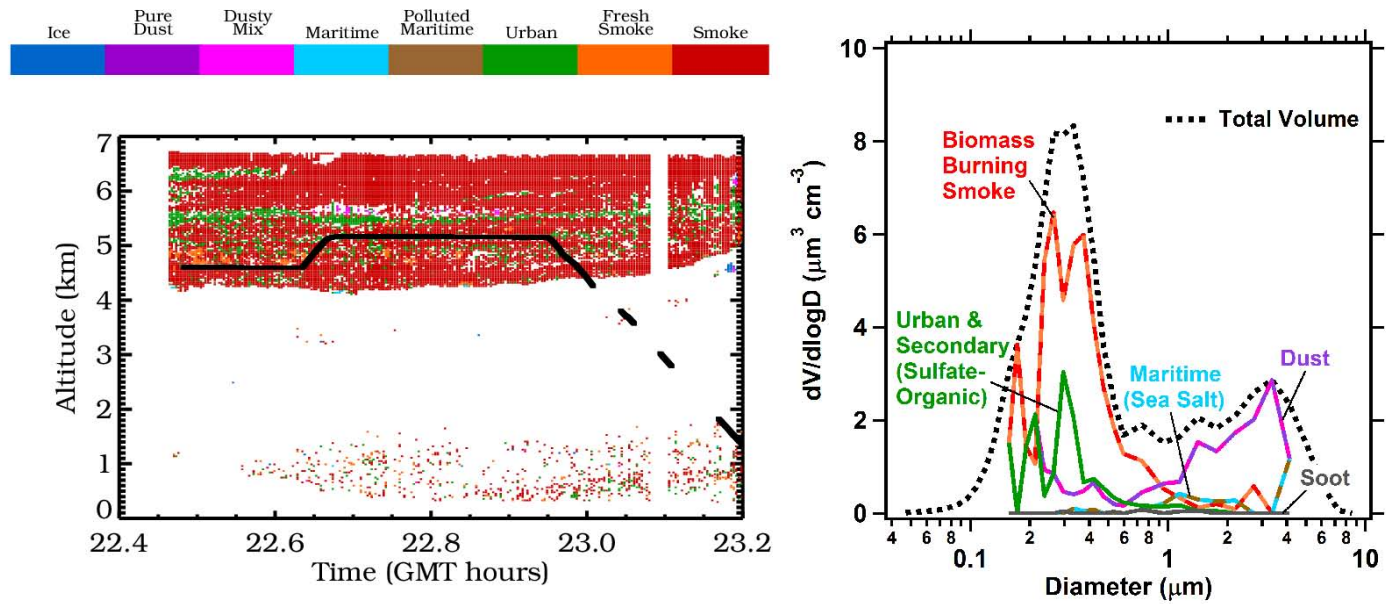

Fig. 16. Aerosol classification from HSRL measurements for 12 April 2008 B-200 flight near Barrow, Alaska during ARCTAS/ARCPAC (left panel) and PALMS aerosol composition data from the NOAA P3 from 22:40-22:57 UT (right panel). Both instruments indicate mainly biomass burning aerosol, consistent with known smoke plumes from fires in Russia (see Warneke et al., 2010). The left panel also shows coincident portions of the flight track profile of the P3 when it was within $30 \mathrm{~km}$ and $1 \mathrm{~h}$ of the HSRL flight track.

over Canada. Urban aerosols were most prominently observed at the lowest altitudes, especially during ARCTAS 1. Smoke, contributed by both the fresh and aged components, was dominant during both ARCTAS 1 and ARCTAS 2. Airborne in situ measurements acquired during the ARCTAS 1 mission also found smoke as the dominant component. The B200 flights during ARCTAS 2 were designed to sample smoke from biomass burning fires so it is expected that smoke would dominate. Note also that the lower altitudes had higher concentrations of fresh smoke, especially during ARCTAS 2.

The ARCTAS mission also provided an opportunity to compare the classification measurements with airborne in situ measurements of size and composition. On 12 and 19 April 2008, the NASA B200 flew patterns that enabled HSRL to acquire coincident data with in situ sensors on the NOAA WP-3D aircraft, which was deployed to conduct the airborne Aerosol, Radiation, and cloud Processes affecting Arctic Climate (ARCPAC) field study (Warneke et al., 2010; Brock et al., 2011). The WP-3D deployed a suite of instruments for measuring gas, aerosol, and radiation properties, including optical particle counters for measuring the aerosol volume distribution and the Particle Analysis by Laser Mass Spectrometry (PALMS) instrument for size-resolved singleparticle composition (Froyd et al., 2009). Figure 16 shows the results of the HSRL aerosol classification and aerosol volume distribution and particle classification distributions from the PALMS on 12 April 2008. As described by Warneke et al. (2010), the compositional resolved volume distributions represent the product of the number fraction of each aerosol type in a given size bin and the total aerosol volume for that size bin. Figure 16 shows that biomass burning material was the largest component, with other contributions from sulfate/organic and mineral dust. The HSRL aerosol classification results are consistent with this, with the majority of the aerosol types classified as smoke and a smaller portion classified as urban. Figure 17 shows another example comparing the HSRL aerosol classification and volume distribution and particle classification distributions from the PALMS for data acquired on 19 April 2008 during ARCTAS 1. These data were acquired in the vicinity of Barrow, Alaska, when there was an extensive amount of biomass burning smoke over this region (Warneke et al., 2010). This smoke was produced by fires in Russia. Figure 17 shows that the HSRL aerosol classification indicated that biomass burning aerosols were present in most of the troposphere over the Barrow region during this flight. The PALMS measurements also show that biomass burning smoke was dominant during these flights. Additional investigations comparing the HSRL aerosol classification results with airborne in situ measurements acquired during ARCTAS and other field campaigns are ongoing.

The contributions of each type to the total optical depth measured by HSRL during each mission are shown in Fig. 18. Some missions were dominated by a single type; for example, maritime air in the Caribbean campaign, a field mission primarily over water in a location chosen for clean conditions. The urban type dominated the TexAQS/GoMACCS campaign, which occurred near Houston, Texas; the Birmingham campaign; the San Joaquin Valley (California) campaign (Lewis et al., 2010); and CALIPSO validation flights, which have primarily occurred over the East coast of the United States. The urban type was also seen in large amounts in the MILAGRO campaign near Mexico City, in that case along with large amounts of dust. CHAPS and RACORO campaigns near Oklahoma City also saw both pollution and dust. The ice classification is present in significant amounts only in the spring deployment of the 

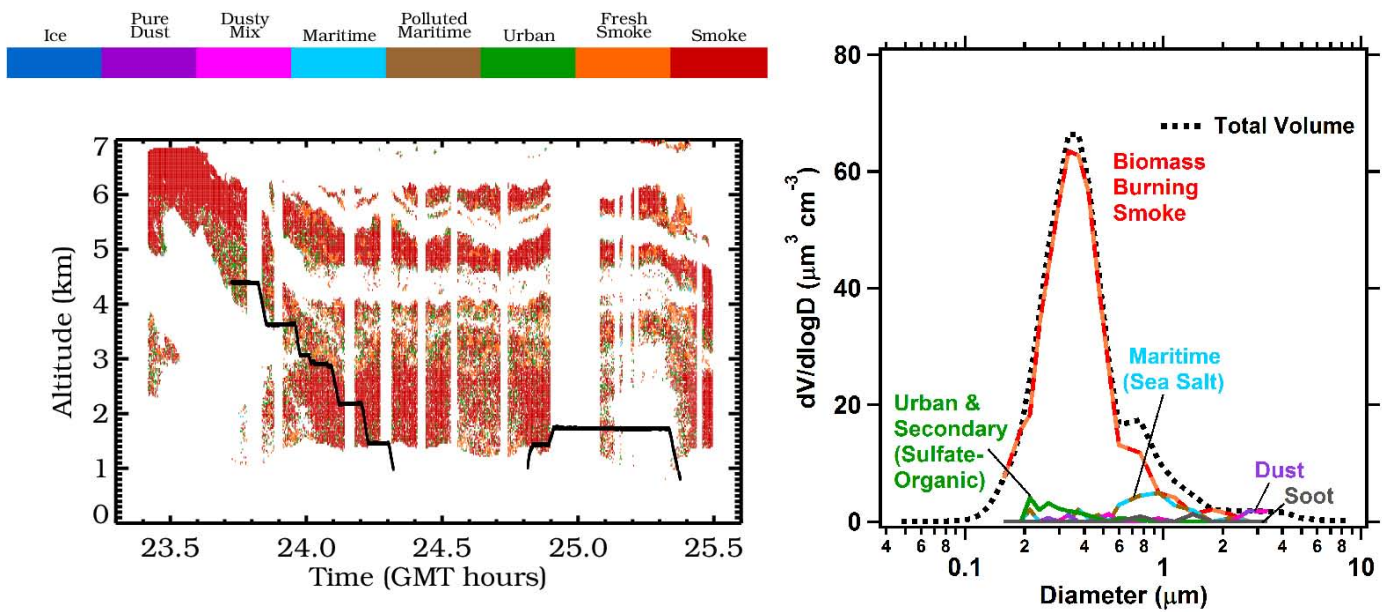

Fig. 17. Left panel: aerosol classification from HSRL measurements onboard the B200 for 19 April 2008 B-200 flight near Barrow, Alaska during ARCTAS/ARCPAC, with black trace showing coincident portions of the flight track profile of the NOAA P3 when the two aircraft were within $30 \mathrm{~km}$ and $1 \mathrm{~h}$ of each other. The time axis indicates GMT time on 19 April. Times beyond $24 \mathrm{~h}$ are used to indicate the early hours of 20 April GMT. Right panel: PALMS aerosol composition data from the NOAA P3 between 00:03-00:19 GMT (20 April). The PALMS instrument indicates a very dense biomass burning plume between 1.5 and $3 \mathrm{~km}$, and the HSRL classification also indicates smoke throughout. These results are consistent with known smoke plumes from fires in Russia (see Warneke et al., 2010).

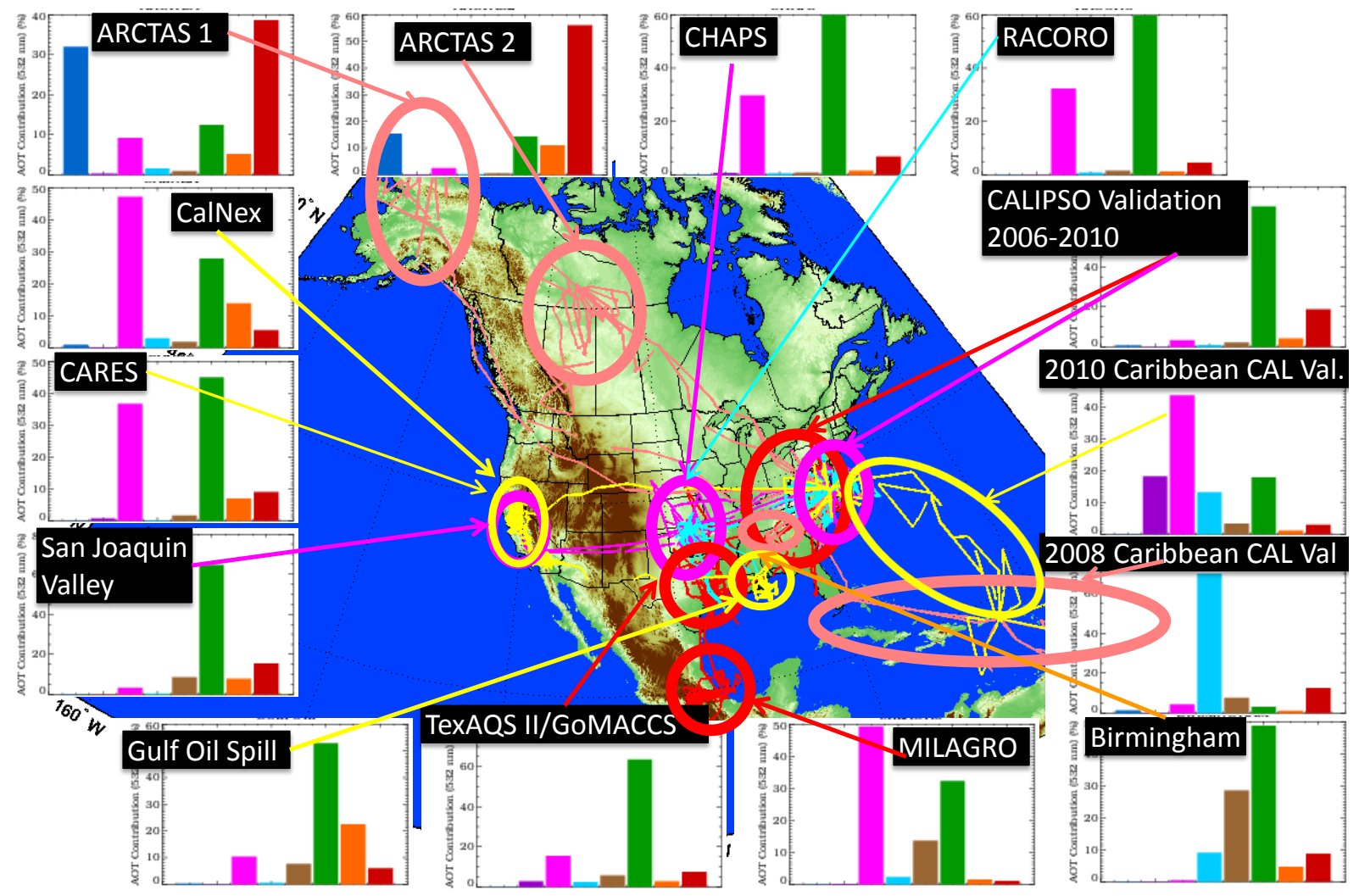

Fig. 18. All HSRL missions through 2010 are shown, along with the partitioning of total optical depth among the eight aerosol types for each of these missions. Several CALIPSO validation campaigns in the Eastern US and off the east coast have been grouped together in the single category "CALIPSO Validation" in this figure. 
ARCTAS campaign (ARCTAS 1), in which biomass burning smoke (Warneke et al., 2010) was the other predominant component. Smoke also dominated the summer deployment of ARCTAS (ARCTAS 2) (Jacob et al., 2010).

\section{Summary}

A method to qualitatively classify aerosol types based on airborne HSRL measurements of aerosol intensive parameters has been presented here. Several examples show how these aerosol parameters vary with different aerosol types and can therefore be used to discriminate among these types. For example, the HSRL measurements show that ice and dust can in many cases be distinguished using the lidar ratio, and to a lesser extent, particle depolarization at $532 \mathrm{~nm}$. Urban and biomass burning smoke aerosols, which typically have somewhat similar lidar ratios (at $532 \mathrm{~nm}$ ) and backscatter color ratios $(532 / 1064 \mathrm{~nm})$, can be difficult to distinguish; however, the HSRL measurements show that urban and biomass burning aerosols can have significant differences in spectral particle depolarization and that these differences can be used to help distinguish these aerosols. Further improvements in distinguishing urban and biomass burning smoke could be realized through the use of additional backscatter and extinction measurements at $355 \mathrm{~nm}$ (Müller et al., 2007a). The HSRL measurements also show differences in the lidar ratio between fresh and aged smoke. This classification method uses HSRL measurements of the lidar ratio at $532 \mathrm{~nm}$, backscatter color ratio, 532-nm depolarization, and depolarization spectral ratio to infer the appropriate type. The method, which uses a sample set of known aerosol cases to help define the set of lidar parameters appropriate for each type, was applied to the extensive set of airborne HSRL observations acquired since 2006. The classification results were used together with the HSRL measurements of aerosol optical depth to apportion the aerosol optical depth among the various aerosol types. These results show that the dominant aerosol types in terms of aerosol optical depth vary significantly with location. Aerosol classification results using HSRL measurements have already been useful in field campaigns, as evidenced by published examples of the identification of smoke aerosols during the NASA Arctic Research of the Composition of the Troposphere from Aircraft and Satellites (ARCTAS) mission (Warneke et al., 2010) and urban aerosols during the MILAGRO campaign (Molina et al., 2010).

The HSRL classification results were used to examine the vertical variability of aerosol types observed during the NASA ARCTAS mission that was conducted during the spring and summer 2008. The results show that biomass burning aerosol was the dominant aerosol type for both the spring and summer deployments, which is consistent with other measurements (Jacob et al., 2010; Warneke et al., 2010; Brock et al., 2011; Shinozuka et al., 2010). In two cases, the HSRL classification results were shown to be consistent with aerosol types derived from coincident airborne in situ measurements.

As will be discussed in the companion paper, more aerosol type information from measurements such as HSRL can potentially be used to improve model inputs and assess the ability of global and regional models to accurately portray aerosol (Ferrare et al., 2012). Accurate aerosol discrimination can also improve retrievals of aerosol properties from space. The CALIPSO aerosol algorithm, for example, requires an a priori estimate of the lidar ratio in the retrieval of aerosol extinction (Omar et al., 2009). The HSRL measurements described here show how the lidar ratio varies with these major aerosol types. A technique for classifying aerosol from lidar measurements such as the one presented here may be useful as a means of constraining advance multiwavelength lidar retrievals such as those using inversion with regularization (Müller et al., 1999; Veselovskii et al., 2002). In such cases, the typing results can essentially serve as a preinversion classifier to more efficiently and rapidly solve for aerosol microphysical parameters, potentially allowing these advanced retrievals to become suitable for operational use from future spaceborne lidars.

Acknowledgements. Funding for this research came from the NASA HQ Science Mission Directorate Radiation Sciences Program; the NASA CALIPSO project; and the US Department of Energy's Atmospheric Science Program Atmospheric System Research, an Office of Science, Office of Biological and Environmental Research program, under Grant No. DE-AI02-05ER63985. The authors also acknowledge the NOAA Air Resources Laboratory (ARL) for the provision of the HYSPLIT transport and dispersion model and READY website (http://www.arl.noaa.gov/ready.php) used for some of the analysis described in this publication. The authors would also like to thank the NASA Langley B200 King Air flight crew for their outstanding work in support of HSRL measurements.

Edited by: M. Wendisch

\section{References}

Ackermann, J.: The extinction-to-backscatter ratio of tropospheric aerosol: A numerical study, J. Atmos. Ocean. Tech., 15, $1043-$ 1050, 1998.

Alados-Arboledas, L., Müller, D., Guerrero-Rascado, J. L., NavasGuzmán, F., Pérez-Ramírez, D., and Olmo, F. J.: Optical and microphysical properties of fresh biomass burning aerosol retrieved by Raman lidar, and star-and sun-photometry, Geophys. Res. Lett., 38, L01807, doi:10.1029/2010g1045999, 2011.

Alvarez, J. M., Vaughan, M. A., Hostetler, C. A., Hunt, W. H., and Winker, D. M.: Calibration Technique for PolarizationSensitive Lidars, J. Atmos. Ocean. Tech., 23, 683-699, doi:10.1175/jtech1872.1, 2006.

Amiridis, V., Balis, D. S., Giannakaki, E., Stohl, A., Kazadzis, S., Koukouli, M. E., and Zanis, P.: Optical characteristics of biomass burning aerosols over Southeastern Europe determined 
from UV-Raman lidar measurements, Atmos. Chem. Phys., 9, 2431-2440, doi:10.5194/acp-9-2431-2009, 2009.

Anderson, T. L., Masonis, S. J., Covert, D. S., Charlson, R. J., and Rood, M. J.: In situ measurement of the aerosol extinction-tobackscatter ratio at a polluted continental site, J. Geophys. Res., 105, 26907-26915, 2000.

Ansmann, A., Riebesell, M., and Weitkamp, C.: Measurement of Atmospheric Aerosol Extinction Profiles with a Raman Lidar, Opt. Lett., 15, 746-748, 1990.

Brock, C. A., Cozic, J., Bahreini, R., Froyd, K. D., Middlebrook, A. M., McComiskey, A., Brioude, J., Cooper, O. R., Stohl, A., Aikin, K. C., de Gouw, J. A., Fahey, D. W., Ferrare, R. A., Gao, R.-S., Gore, W., Holloway, J. S., Hübler, G., Jefferson, A., Lack, D. A., Lance, S., Moore, R. H., Murphy, D. M., Nenes, A., Novelli, P. C., Nowak, J. B., Ogren, J. A., Peischl, J., Pierce, R. B., Pilewskie, P., Quinn, P. K., Ryerson, T. B., Schmidt, K. S., Schwarz, J. P., Sodemann, H., Spackman, J. R., Stark, H., Thomson, D. S., Thornberry, T., Veres, P., Watts, L. A., Warneke, C., and Wollny, A. G.: Characteristics, sources, and transport of aerosols measured in spring 2008 during the aerosol, radiation, and cloud processes affecting Arctic Climate (ARCPAC) Project, Atmos. Chem. Phys., 11, 2423-2453, doi:10.5194/acp-11-24232011, 2011.

Burton, S. P., Ferrare, R. A., Hostetler, C. A., Hair, J. W., Kittaka, C., Vaughan, M. A., Obland, M. D., Rogers, R. R., Cook, A. L., Harper, D. B., and Remer, L. A.: Using airborne high spectral resolution lidar data to evaluate combined active plus passive retrievals of aerosol extinction profiles, J. Geophys. Res.-Atmos., 115, D00H15, doi:10.1029/2009jd012130, 2010.

Campbell, J. R., Welton, E. J., Spinhirne, J. D., Ji, Q., Tsay, S. C., Piketh, S. J., Barenbrug, M., and Holben, B. N.: Micropulse lidar observations of tropospheric aerosols over northeastern South Africa during the ARREX and SAFARI 2000 dry season experiments, J. Geophys. Res.-Atmos., 108, 8497, doi:10.1029/2002jd002563, 2003.

Cattrall, C., Reagan, J., Thome, K., and Dubovik, O.: Variability of aerosol and spectral lidar and backscatter and extinction ratios of key aerosol types derived from selected Aerosol Robotic Network locations, J. Geophys. Res.-Atmos., 110, D10S11, doi:10.1029/2004jd005124, 2005.

Chin, M., Ginoux, P., Kinne, S., Torres, O., Holben, B. N., Duncan, B. N., Martin, R. V., Logan, J. A., Higurashi, A., and Nakajima, T.: Tropospheric Aerosol Optical Thickness from the GOCART Model and Comparisons with Satellite and Sun Photometer Measurements, J. Atmos. Sci., 59, 461-483, 2002.

Curry, J. A., Meyer, F. G., Radke, L. F., Brock, C. A., and Ebert, E. E.: Occurrence and Characteristics of Lower Tropospheric Ice Crystals in the Arctic, Int. J. Climatol., 10, 749-764, 1990.

Davis, K. J., Gamage, N., Hagelberg, C. R., Kiemle, C., Lenschow, D. H., and Sullivan, P. P.: An objective method for deriving atmospheric structure from airborne lidar observations, J. Atmos. Ocean. Tech., 17, 1455-1468, 2000.

de Foy, B., Burton, S. P., Ferrare, R. A., Hostetler, C. A., Hair, J. W., Wiedinmyer, C., and Molina, L. T.: Aerosol plume transport and transformation in high spectral resolution lidar measurements and WRF-Flexpart simulations during the MILAGRO Field Campaign, Atmos. Chem. Phys., 11, 3543-3563, doi:10.5194/acp-11-3543-2011, 2011.

Dempster, A. P., Laird, N. M., and Rubin, D. B.: Maximum
Likelihood from Incomplete Data via the EM Algorithm, J. Roy. Stat. Soc. B, 39, 1-38, 1977.

Draxler, R. R. and Rolph, G. D.: HYSPLIT (HYbrid Single-Particle Lagrangian Integrated Trajectory) Model access via NOAA ARL READY Website http://ready.arl.noaa.gov/ HYSPLIT.php, last access: January 2012, NOAA Air Resources Laboratory, Silver Spring, MD, 2012.

Dubovik, O., Holben, B., Eck, T. F., Smirnov, A., Kaufman, Y. J., King, M. D., Tanré, D., and Slutsker, I.: Variability of absorption and optical properties of key aerosol types observed in worldwide locations, J. Atmos. Sci., 59, 590-608, 2002.

Eloranta, E. W.: High spectral resolution lidar, in: Lidar: RangeResolved Optical Remote Sensing of the Atmosphere, edited by: Weitkamp, K., Springer, New York, 143-163, 2005.

Esselborn, M., Wirth, M., Fix, A., Weinzierl, B., Rasp, K., Tesche, M., and Petzold, A.: Spatial distribution and optical properties of Saharan dust observed by airborne high spectral resolution lidar during SAMUM 2006, Tellus B, 61, 131-143, doi:10.1111/j.1600-0889.2008.00394.x, 2009.

Fernald, F. G.: Analysis of Atmospheric Lidar Observations - Some Comments, Appl. Optics, 23, 652-653, 1984.

Fernald, F. G., Herman, B. M., and Reagan, J. A.: Determination of Aerosol Height Distributions by Lidar, J. Appl. Meteorol., 11, 482-489, doi:10.1175/15200450(1972)011<0482:doahdb>2.0.co;2, 1972.

Ferrare, R. A., Burton, S. P., Hostetler, C. A., Hair, J. W., Rogers, R. R., Obland, M. D., Butler, C. F., Cook, A. L., Harper, D. B., Chin, M., Omar, A., and Vaughan, M. A.: Aerosol classification of airborne High Spectral Resolution Lidar measurements comparisons with CALIOP and GOCART, in preparation, 2012.

Fiebig, M., Petzold, A., Wandinger, U., Wendisch, M., Kiemle, C., Stifter, A., Ebert, M., Rother, T., and Leiterer, U.: Optical closure for an aerosol column: Method, accuracy, and inferable properties applied to a biomass-burning aerosol and its radiative forcing, J. Geophys. Res., 107, 8130, doi:10.1029/2000jd000192, 2002.

Freudenthaler, V., Esselborn, M., Wiegner, M., Heese, B., Tesche, M., Ansmann, A., Müller, D., Althausen, D., Wirth, M., Fix, A., Ehret, G., Knippertz, P., Toledano, C., Gasteiger, J., Garhammer, M., and Seefeldner, M.: Depolarization ratio profiling at several wavelengths in pure Saharan dust during SAMUM 2006, Tellus B, 61, 165-179, doi:10.1111/j.1600-0889.2008.00396.x, 2009.

Froyd, K. D., Murphy, D. M., Sanford, T. J., Thomson, D. S., Wilson, J. C., Pfister, L., and Lait, L.: Aerosol composition of the tropical upper troposphere, Atmos. Chem. Phys., 9, 4363-4385, doi:10.5194/acp-9-4363-2009, 2009.

Giannakaki, E., Balis, D. S., Amiridis, V., and Zerefos, C.: Optical properties of different aerosol types: seven years of combined Raman-elastic backscatter lidar measurements in Thessaloniki, Greece, Atmos. Meas. Tech., 3, 569-578, doi:10.5194/amt-3569-2010, 2010.

Girard, E. and Blanchet, J.-P.: Microphysical Parameterization of Arctic Diamond Dust, Ice Fog, and Thin Stratus for Climate Models, J. Atmos. Sci., 58, 1181-1198, doi:10.1175/15200469(2001)058<1181:MPOADD>2.0.CO;2, 2001.

GLOBE Task Team, Hastings, D. A., Dunbar, P. K., Elphingstone, G. M., Bootz, M., Murakami, H., Maruyama, H., Masaharu, H., Holland, P., Payne, J., Bryant, N. A., Logan, T. L., Müller, 
J.-P., Schreier, G., and MacDonald, J. S.: The Global Land Onekilometer Base Elevation (GLOBE) Digital Elevation Model, Version 1.0, edited by: National Oceanic and Atmospheric Administration, N. G. D. C., Boulder, Colorado, 1999.

Greenaway, K. R.: Experiences with arctic flying weather, Publications of the Royal Meteorological Society, Canadian Branch, 1, 1950.

Groß, S., Tesche, M., Freudenthaler, V., Toledano, C., Wiegner, M., Ansmann, A., Althausen, D., and Seefeldner, M.: Characterization of Saharan dust, marine aerosols and mixtures of biomassburning aerosols and dust by means of multi-wavelength depolarization and Raman lidar measurements during SAMUM 2, Tellus B, 63, 706-724, doi:10.1111/j.1600-0889.2011.00556.x, 2011.

Grund, C. J. and Eloranta, E. W.: University-of-Wisconsin High Spectral Resolution Lidar, Opt. Eng., 30, 6-12, 1991.

Hair, J. W., Hostetler, C. A., Cook, A. L., Harper, D. B., Ferrare, R. A., Mack, T. L., Welch, W., Izquierdo, L. R., and Hovis, F. E.: Airborne High Spectral Resolution Lidar for profiling aerosol optical properties, Appl. Optics, 47, 6734-6752, doi:10.1364/AO.47.006734, 2008.

Heese, B. and Wiegner, M.: Vertical aerosol profiles from Raman polarization lidar observations during the dry season AMMA field campaign, J. Geophys. Res., 113, D00C11, doi:10.1029/2007jd009487, 2008.

Heintzenberg, J.: The SAMUM-1 experiment over Southern Morocco: overview and introduction, Tellus B, 61, 2-11, doi:10.1111/j.1600-0889.2008.00403.x, 2009.

Hill, T. and Lewicki, P.: STATISTICS Methods and Applications, StatSoft, Tulsa, OK, 2007.

Hoff, R. M.: Vertical Structure of Arctic Haze Observed by Lidar, J. Appl. Meteorol., 27, 125-139, 1988.

Holben, B. N., Eck, T. F., Slutsker, I., Tanré, D., Buis, J. P., Setzer, A., Vermote, E., Reagan, J. A., Kaufman, Y. J., Nakajima, T., Lavenu, F., Jankowiak, I., and Smirnov, A.: AERONET - A federated instrument network and data archive for aerosol characterization, Remote Sens. Environ., 66, 1-16, 1998.

Jacob, D. J., Crawford, J. H., Maring, H., Clarke, A. D., Dibb, J. E., Emmons, L. K., Ferrare, R. A., Hostetler, C. A., Russell, P. B., Singh, H. B., Thompson, A. M., Shaw, G. E., McCauley, E., Pederson, J. R., and Fisher, J. A.: The Arctic Research of the Composition of the Troposphere from Aircraft and Satellites (ARCTAS) mission: design, execution, and first results, Atmos. Chem. Phys., 10, 5191-5212, doi:10.5194/acp-10-5191-2010, 2010

Kahn, R., Gaitley, B. J., Martonchik, J. V., Diner, D. J., Crean, K. A., and Holben, B.: Multiangle Imaging Spectroradiometer (MISR) global aerosol optical depth validation based on 2 years of coincident Aerosol Robotic Network (AERONET) observations, J. Geophys. Res.-Atmos., 110, D10S04, doi:10.1029/2004jd004706, 2005.

Kent, G. S., Trepte, C. R., Skeens, K. M., and Winker, D. M.: LITE and SAGE II measurements of aerosols in the southern hemisphere upper troposphere, J. Geophys. Res., 103, 19111-19127, doi:10.1029/98jd00364, 1998.

Klett, J. D.: Stable Analytical Inversion Solution for Processing Lidar Returns, Appl. Optics, 20, 211-220, 1981.

Knobelspiesse, K., Cairns, B., Ottaviani, M., Ferrare, R., Hair, J., Hostetler, C., Obland, M., Rogers, R., Redemann, J., Shinozuka,
Y., Clarke, A., Freitag, S., Howell, S., Kapustin, V., and McNaughton, C.: Combined retrievals of boreal forest fire aerosol properties with a polarimeter and lidar, Atmos. Chem. Phys., 11, 7045-7067, doi:10.5194/acp-11-7045-2011, 2011.

Léon, J. F., Tanré, D., Pelon, J., Kaufman, Y. J., Haywood, J. M., and Chatenet, B.: Profiling of a Saharan dust outbreak based on a synergy between active and passive remote sensing, J. Geophys. Res.-Atmos., 108, 8575, doi:10.1029/2002jd002774, 2003.

Lewis, J., De Young, R., Ferrare, R., and Chu, D. A.: Comparison of summer and winter California central valley aerosol distributions from lidar and MODIS measurements, Atmos. Environ., 44, 4510-4520, doi:10.1016/j.atmosenv.2010.07.006, 2010.

Liu, Z. Y., Omar, A., Vaughan, M., Hair, J., Kittaka, C., Hu, Y. X., Powell, K., Trepte, C., Winker, D., Hostetler, C., Ferrare, R., and Pierce, R.: CALIPSO lidar observations of the optical properties of Saharan dust: A case study of long-range transport, J. Geophys. Res.-Atmos., 113, D07207, doi:10.1029/2007jd008878, 2008.

MacQueen, J.: Some Methods for Classification and Analysis of Multivariate Observations, Proceedings of 5th Berkeley Symposium on Mathematical Statistics and Probability, 281-297, 1967.

Mahalanobis, P. C.: On the Generalized Distance in Statistics, Proc. Natl. Inst. Sci. India, 2, 49-55, 1936.

McCormick, M. P., Winker, D. M., Browell, E. V., Coakley, J. A., Gardner, C. S., Hoff, R. M., Kent, G. S., Melfi, S. H., Menzies, R. T., Platt, C. M. R., Randall, D. A., and Reagan, J. A.: Scientific Investigations Planned for the Lidar In-Space Technology Experiment (LITE), B. Am. Meteorol. Soc., 74, 205-214, doi:10.1175/1520-0477(1993)074<0205:sipftl>2.0.co;2, 1993.

McNaughton, C. S., Clarke, A. D., Kapustin, V., Shinozuka, Y., Howell, S. G., Anderson, B. E., Winstead, E., Dibb, J., Scheuer, E., Cohen, R. C., Wooldridge, P., Perring, A., Huey, L. G., Kim, S., Jimenez, J. L., Dunlea, E. J., DeCarlo, P. F., Wennberg, P. O., Crounse, J. D., Weinheimer, A. J., and Flocke, F.: Observations of heterogeneous reactions between Asian pollution and mineral dust over the Eastern North Pacific during INTEX-B, Atmos. Chem. Phys., 9, 8283-8308, doi:10.5194/acp-9-8283-2009, 2009.

Mishchenko, M. and Sassen, K.: Depolarization of lidar returns by small ice crystals: An application to contrails, Geophys. Res. Lett., 25, 309-312, 1998.

Molina, L. T., Madronich, S., Gaffney, J. S., Apel, E., de Foy, B., Fast, J., Ferrare, R., Herndon, S., Jimenez, J. L., Lamb, B., Osornio-Vargas, A. R., Russell, P., Schauer, J. J., Stevens, P. S., Volkamer, R., and Zavala, M.: An overview of the MILAGRO 2006 Campaign: Mexico City emissions and their transport and transformation, Atmos. Chem. Phys., 10, 8697 8760, doi:10.5194/acp-10-8697-2010, 2010.

Müller, D., Wandinger, U., and Ansmann, A.: Microphysical particle parameters from extinction and backscatter lidar data by inversion with regularization: theory, Appl. Optics, 38, 23462357, 1999.

Müller, D., Ansmann, A., Mattis, I., Tesche, M., Wandinger, U., Althausen, D., and Pisani, G.: Aerosol-type-dependent lidar ratios observed with Raman lidar, J. Geophys. Res.-Atmos., 112, D16202, doi:10.1029/2006jd008292, 2007a.

Müller, D., Mattis, I., Ansmann, A., Wandinger, U., Ritter, C., and Kaiser, D.: Multiwavelength Raman lidar observations of particle growth during long-range transport of forest-fire 
smoke in the free troposphere, Geophys. Res. Lett., 34, L05803, doi:10.1029/2006gl027936, 2007b.

Murayama, T., Furushima, M., Oda, A., and Iwasaka, N.: Depolarization ratio measurements in the atmospheric boundary layer by lidar in Tokyo, J. Meteorol. Soc. Jpn., 74, 571-578, 1996.

Murayama, T., Okamoto, H., Kaneyasu, N., Kamataki, H., and Miura, K.: Application of lidar depolarization measurement in the atmospheric boundary layer: Effects of dust and sea-salt particles, J. Geophys. Res.-Atmos., 104, 31781-31792, 1999.

Murayama, T., Masonis, S. J., Redemann, J., Anderson, T. L., Schmid, B., Livingston, J. M., Russell, P. B., Huebert, B., Howell, S. G., McNaughton, C. S., Clarke, A., Abo, M., Shimizu, A., Sugimoto, N., Yabuki, M., Kuze, H., Fukagawa, S., Maxwell-Meier, K., Weber, R. J., Orsini, D. A., Blomquist, B., Bandy, A., and Thornton, D.: An intercomparison of lidarderived aerosol optical properties with airborne measurements near Tokyo during ACE-Asia, J. Geophys. Res.-Atmos., 108, 8651, doi:10.1029/2002jd003259, 2003.

Murayama, T., Müller, D., Wada, K., Shimizu, A., Sekiguchi, M., and Tsukamoto, T.: Characterization of Asian dust and Siberian smoke with multiwavelength Raman lidar over Tokyo, Japan in spring 2003, Geophys. Res. Lett., 31, doi:10.1029/2004g1021105, 2004.

National Research Council: Earth Science and Applications from Space: National Imperatives for the Next Decade and Beyond, The National Academies Press, Washington, DC, 400 pp., 2007.

Noh, Y. M., Müller, D., Shin, D. H., Lee, H., Jung, J. S., Lee, K. H., Cribb, M., Li, Z. Q., and Kim, Y. J.: Optical and microphysical properties of severe haze and smoke aerosol measured by integrated remote sensing techniques in Gwangju, Korea, Atmos. Environ., 43, 879-888, doi:10.1016/j.atmosenv.2008.10.058, 2009.

Omar, A. H., Won, J.-G., Winker, D. M., Yoon, S.-C., Dubovik, O., and McCormick, M. P.: Development of global aerosol models using cluster analysis of Aerosol Robotic Network (AERONET) measurements, J. Geophys. Res., 110, D10S14, doi:10.1029/2004jd004874, 2005.

Omar, A. H., Winker, D. M., Kittaka, C., Vaughan, M. A., Liu, Z. Y., Hu, Y. X., Trepte, C. R., Rogers, R. R., Ferrare, R. A., Lee, K. P., Kuehn, R. E., and Hostetler, C. A.: The CALIPSO Automated Aerosol Classification and Lidar Ratio Selection Algorithm, J. Atmos. Ocean. Tech., 26, 1994-2014, doi:10.1175/2009jtecha1231.1, 2009.

Ottaviani, M., Cairns, B., Chowdhary, J., Van Diedenhoven, B., Knobelspiesse, K., Hostetler, C., Ferrare, R., Burton, S., Hair, J., Obland, M. D., and Rogers, R.: Polarimetric retrievals of surface properties in the region affected by the Deepwater Horizon oil spill, Remote Sens. Environ., in review, 2012.

Parrish, D. D., Allen, D. T., Bates, T. S., Estes, M., Fehsenfeld, F. C., Feingold, G., Ferrare, R., Hardesty, R. M., Meagher, J. F., Nielsen-Gammon, J. W., Pierce, R. B., Ryerson, T. B., Seinfeld, J. H., and Williams, E. J.: Overview of the Second Texas Air Quality Study (TexAQS II) and the Gulf of Mexico Atmospheric Composition and Climate Study (GoMACCS), J. Geophys. Res.Atmos., 114, D00F13, doi:10.1029/2009jd011842, 2009.

Powell, D. M., Reagan, J. A., Rubio, M. A., Erxleben, W. H., and Spinhirne, J. D.: ACE-2 multiple angle micro-pulse lidar observations from Las Galletas, Tenerife, Canary Islands, Tellus B, 52, 652-661, doi:10.1034/j.1600-0889.2000.00059.x, 2000.
Redemann, J., Zhang, Q., Livingston, J., Russell, P., Shinozuka, Y., Clarke, A., Johnson, R., and Levy, R.: Testing aerosol properties in MODIS Collection 4 and 5 using airborne sunphotometer observations in INTEX-B/MILAGRO, Atmos. Chem. Phys., 9, 8159-8172, doi:10.5194/acp-9-8159-2009, 2009.

Remer, L. A., Kaufman, Y. J., Tanré, D., Mattoo, S., Chu, D. A., Martins, J. V., Li, R. R., Ichoku, C., Levy, R. C., Kleidman, R. G., Eck, T. F., Vermote, E., and Holben, B. N.: The MODIS aerosol algorithm, products, and validation, J. Atmos. Sci., 62, 947-973, 2005.

Rodgers, C. D.: Inverse Methods for Atmospheric Sounding: Theory and Practice, Series on Atmospheric, Oceanic and Planetary Physics, 2, edited by: Taylor, F. W., World Scientific, New Jersey, 2000.

Rogers, R. R., Hair, J. W., Hostetler, C. A., Ferrare, R. A., Obland, M. D., Cook, A. L., Harper, D. B., Burton, S. P., Shinozuka, Y., McNaughton, C. S., Clarke, A. D., Redemann, J., Russell, P. B., Livingston, J. M., and Kleinman, L. I.: NASA LaRC airborne high spectral resolution lidar aerosol measurements during MILAGRO: observations and validation, Atmos. Chem. Phys., 9, 4811-4826, doi:10.5194/acp-9-4811-2009, 2009.

Russell, P. B., Bergstrom, R. W., Shinozuka, Y., Clarke, A. D., DeCarlo, P. F., Jimenez, J. L., Livingston, J. M., Redemann, J., Dubovik, O., and Strawa, A.: Absorption Angstrom Exponent in AERONET and related data as an indicator of aerosol composition, Atmos. Chem. Phys., 10, 1155-1169, doi:10.5194/acp10-1155-2010, 2010.

Saha, A., O’Neill, N. T., Eloranta, E., Stone, R. S., Eck, T. F., Zidane, S., Daou, D., Lupu, A., Lesins, G., Shiobara, M., and McArthur, L. J. B.: Pan-Arctic sunphotometry during the ARCTAS-A campaign of April 2008, Geophys. Res. Lett., 37, L05803, doi:10.1029/2009g1041375, 2010.

Sakai, T., Nagai, T., Nakazato, M., Mano, Y., and Matsumura, T.: Ice Clouds and Asian Dust Studied with Lidar Measurements of Particle Extinction-to-Backscatter Ratio, Particle Depolarization, and Water-Vapor Mixing Ratio over Tsukuba, Appl. Optics, 42, 7103-7116, doi:10.1364/AO.42.007103, 2003.

Sakai, T., Nagai, T., Zaizen, Y., and Mano, Y.: Backscattering linear depolarization ratio measurements of mineral, sea-salt, and ammonium sulfate particles simulated in a laboratory chamber, Appl. Optics, 49, 4441-4449, 2010.

Sasano, Y. and Browell, E. V.: Light-Scattering Characteristics of Various Aerosol Types Derived from Multiple Wavelength Lidar Observations, Appl. Optics, 28, 1670-1679, 1989.

Sassen, K.: Ice Crystal Habit Discrimination with the Optical Backscatter Depolarization Technique, J. Appl. Meteorol., 16, 425-431, doi:10.1175/15200450(1977)016<0425:ichdwt>2.0.co;2, 1977.

Sassen, K.: Lidar backscatter depolarization technique for cloud and aerosol research, in: Light Scattering by Nonspherical Particles: Theory, Measurements, and Applications, edited by: Mishchenko, M. I., Hovenier, J. W., and Travis, L. D., Academic, San Diego, CA, 2000.

Sassen, K.: Indirect climate forcing over the western US from Asian dust storms, Geophys. Res. Lett., 29, 1465, doi:10.1029/2001g1014051, 2002.

Sassen, K.: Identifying Atmospheric Aerosols with Polarization Lidar, in: Advanced Environmental Monitoring, edited by: Kim, Y. J. and Platt, U., Springer-Verlag, Berlin, 136-142, 2008. 
Sassen, K. and Hsueh, C.-Y.: Contrail properties derived from highresolution polarization lidar studies during SUCCESS, Geophys. Res. Lett., 25, 1165-1168, doi:10.1029/97g103503, 1998.

She, C.-Y.: Spectral Structure of Laser Light Scattering Revisited: Bandwidths of Nonresonant Scattering Lidars, Appl. Optics, 40, 4875-4884, 2001.

She, C. Y., Alvarez, R. J., Caldwell, L. M., and Krueger, D. A.: High-Spectral-Resolution Rayleigh-Mie Lidar Measurement of Vertical Aerosol and Atmospheric Profiles, Appl. Phys. B, 55, 154-158, 1992.

Shimizu, A., Sugimoto, N., Matsui, I., Arao, K., Uno, I., Murayama, T., Kagawa, N., Aoki, K., Uchiyama, A., and Yamazaki, A.: Continuous observations of Asian dust and other aerosols by polarization lidars in China and Japan during ACE-Asia, J. Geophys. Res., 109, D19S17, doi:10.1029/2002jd003253, 2004.

Shinozuka, Y., Redemann, J., Livingston, J. M., Russell, P. B., Clarke, A. D., Howell, S. G., Freitag, S., O’Neill, N. T., Reid, E. A., Johnson, R., Ramachandran, S., McNaughton, C. S., Kapustin, V. N., Brekhovskikh, V., Holben, B. N., and McArthur, L. J. B.: Airborne observation of aerosol optical depth during ARCTAS: vertical profiles, inter-comparison and fine-mode fraction, Atmos. Chem. Phys., 11, 3673-3688, doi:10.5194/acp11-3673-2011, 2011.

Shipley, S. T., Tracy, D. H., Eloranta, E. W., Trauger, J. T., Sroga, J. T., Roesler, F. L., and Weinman, J. A.: High Spectral Resolution Lidar to Measure Optical-Scattering Properties of Atmospheric Aerosols, 1. Theory and Instrumentation, Appl. Optics, 22, 3716-3724, 1983.

Somekawa, T., Yamanaka, C., Fujita, M., and Galvez, M. C.: A new concept to characterize nonspherical particles from multiwavelength depolarization ratios based on T-matrix computation, Part Part Syst. Char., 25, 49-53, doi:10.1002/ppsc.200700009, 2008.

Spinhirne, J. D.: Micro pulse lidar, IEEE T. Geosci. Remote, 31, 48-55, 1993.

Sugimoto, N., Matsui, I., Shimizu, A., Uno, I., Asai, K., Endoh, T., and Nakajima, T.: Observation of dust and anthropogenic aerosol plumes in the Northwest Pacific with a two-wavelength polarization lidar on board the research vessel Mirai, Geophys. Res. Lett., 29, 1901, doi:10.1029/2002g1015112, 2002.

Sugimoto, N. and Lee, C. H.: Characteristics of dust aerosols inferred from lidar depolarization measurements at two wavelengths, Appl. Optics, 45, 7468-7474, 2006.

Tesche, M., Ansmann, A., Müller, D., Althausen, D., Engelmann, R., Freudenthaler, V., and Groß, S.: Vertically resolved separation of dust and smoke over Cape Verde using multiwavelength Raman and polarization lidars during Saharan Mineral Dust Experiment 2008, J. Geophys. Res., 114, D13202, doi:10.1029/2009jd011862, 2009a.

Tesche, M., Ansmann, A., Müller, D., Althausen, D., Mattis, I., Heese, B., Freudenthaler, V., Wiegner, M., Esselborn, M., Pisani, G., and Knippertz, P.: Vertical profiling of Saharan dust with Raman lidars and airborne HSRL in southern Morocco during SAMUM, Tellus B, 61, 144-164, doi:10.1111/j.16000889.2008.00390.x, 2009b.

Tesche, M., Müller, D., Gross, S., Ansmann, A., Althausen, D., Freudenthaler, V., Weinzierl, B., Veira, A., and Petzold, A.: Optical and microphysical properties of smoke over Cape Verde inferred from multiwavelength lidar measurements, Tellus B, 63,
677-694, doi:10.1111/j.1600-0889.2011.00549.x, 2011.

Toon, O. B., Tabazadeh, A., Browell, E. V., and Jordan, J.: Analysis of lidar observations of Arctic polar stratospheric clouds during January 1989, J. Geophys. Res.-Atmos., 105, 20589-20615, 2000.

Veselovskii, I., Kolgotin, A., Griaznov, V., Müller, D., Wandinger, U., and Whiteman, D. N.: Inversion with regularization for the retrieval of tropospheric aerosol parameters from multiwavelength lidar sounding, Appl. Optics, 41, 3685-3699, 2002.

Veselovskii, I., Dubovik, O., Kolgotin, A., Lapyonok, T., Girolamo, P. D., Summa, D., Whiteman, D. N., and Tanré, D.: Application of Randomly Oriented Spheroids for Retrieval of Dust Particle Parameters from Multiwavelength Lidar Measurements, International Laser Radar Conference, St. Petersburg, Russia, 2010.

Wandinger, U., Müller, D., Bockmann, C., Althausen, D., Matthias, V., Bosenberg, J., Weiss, V., Fiebig, M., Wendisch, M., Stohl, A., and Ansmann, A.: Optical and microphysical characterization of biomass-burning and industrial-pollution aerosols from multiwavelength lidar and aircraft measurements, J. Geophys. Res.Atmos., 107, 8125, doi:10.1029/2000jd000202, 2002.

Warneke, C., Froyd, K. D., Brioude, J., Bahreini, R., Brock, C. A., Cozic, J., de Gouw, J. A., Fahey, D. W., Ferrare, R., Holloway, J. S., Middlebrook, A. M., Miller, L., Montzka, S., Schwarz, J. P., Sodemann, H., Spackman, J. R., and Stohl, A.: An important contribution to springtime Arctic aerosol from biomass burning in Russia, Geophys. Res. Lett., 37, L01801, doi:10.1029/2009g1041816, 2010.

Weinzierl, B., Sauer, D., Esselborn, M., Petzold, A., Veira, A., Rose, M., Mund, S., Wirth, M., Ansmann, A., Tesche, M., Gross, S., and Freudenthaler, V.: Microphysical and optical properties of dust and tropical biomass burning aerosol layers in the Cape Verde region - an overview of the airborne in situ and lidar measurements during SAMUM-2, Tellus B, 63, 589-618, doi:10.1111/j.1600-0889.2011.00566.x, 2011.

Welton, E. J., Voss, K. J., Gordon, H. R., Maring, H., Smirnov, A., Holben, B., Schmid, B., Livingston, J. M., Russell, P. B., Durkee, P. A., Formenti, P., and Andreae, M. O.: Ground-based lidar measurements of aerosols during ACE-2: instrument description, results, and comparisons with other ground-based and airborne measurements, Tellus B, 52, 636-651, 2000.

Welton, E. J., Voss, K. J., Quinn, P. K., Flatau, P. J., Markowicz, K., Campbell, J. R., Spinhirne, J. D., Gordon, H. R., and Johnson, J. E.: Measurements of aerosol vertical profiles and optical properties during INDOEX 1999 using micropulse lidars, J. Geophys. Res., 107, 8019, doi:10.1029/2000jd000038, 2002.

Whiteman, D. N., Melfi, S. H., and Ferrare, R. A.: Raman lidar system for the measurement of water vapor and aerosols in the Earth's atmosphere, Appl. Optics, 31, 3068-3082, 1992.

Winker, D. M., Couch, R. H., and McCormick, M. P.: An overview of LITE: NASA's Lidar In-space Technology Experiment, Proc. IEEE, 84, 164-180, 1996.

Winker, D. M., Vaughan, M. A., Omar, A., Hu, Y. X., Powell, K. A., Liu, Z. Y., Hunt, W. H., and Young, S. A.: Overview of the CALIPSO Mission and CALIOP Data Processing Algorithms, J. Atmos. Ocean. Tech., 26, 2310-2323, doi:10.1175/2009jtecha1281.1, 2009. 